\title{
Pareto Optimal Weighting Factor Design of Predictive Current Controller of a Six- Phase Induction Machine based on Particle Swarm Optimization Algorithm
}

Fretes, Hector; Rodas, Jorge; Doval-Gandoy, Jesus; Gomez, Victor; Gomez, Nicolas; Novak, Mateja; Rodriguez, Jose; Dragicevic, Tomislav

\section{Published in:}

IEEE Journal of Emerging and Selected Topics in Power Electronics

Link to article, DOI:

10.1109/JESTPE.2021.3100687

Publication date:

2022

Document Version

Peer reviewed version

Link back to DTU Orbit

Citation $(A P A)$ :

Fretes, H., Rodas, J., Doval-Gandoy, J., Gomez, V., Gomez, N., Novak, M., Rodriguez, J., \& Dragicevic, T. (2022). Pareto Optimal Weighting Factor Design of Predictive Current Controller of a Six-Phase Induction Machine based on Particle Swarm Optimization Algorithm. IEEE Journal of Emerging and Selected Topics in Power Electronics, 10(1), 207-219. https://doi.org/10.1109/JESTPE.2021.3100687

\section{General rights}

Copyright and moral rights for the publications made accessible in the public portal are retained by the authors and/or other copyright owners and it is a condition of accessing publications that users recognise and abide by the legal requirements associated with these rights.

- Users may download and print one copy of any publication from the public portal for the purpose of private study or research.

- You may not further distribute the material or use it for any profit-making activity or commercial gain

- You may freely distribute the URL identifying the publication in the public portal 


\title{
Pareto Optimal Weighting Factor Design of Predictive Current Controller of a Six-Phase Induction Machine based on Particle Swarm Optimization Algorithm
}

\author{
Hector Fretes, Jorge Rodas, Senior Member, IEEE, Jesus Doval-Gandoy, Member, IEEE, Victor Gomez, Nicolas \\ Gomez, Mateja Novak, Member, IEEE, Jose Rodriguez, Life Fellow, IEEE, and Tomislav Dragičević, Senior \\ Member, IEEE
}

\begin{abstract}
Finite-set model predictive control (FS-MPC) as predictive current control (PCC) is considered an exciting option for the stator current control of multiphase machines due to their control flexibility and easy inclusion of constraints. The weighting factors (WFs) of PCC must be tuned for the variables of interest, such as the machine losses $x-y$ currents, typically performed by trial and error procedure. Tuning methods based on artificial neural network (ANN) or the coefficient of variation were proposed for three-phase inverter and motor drive applications. However, the extension of this concept to the multiphase machine application is not straightforward, and only empirical procedures have been reported. In this context, this paper proposes an optimal method to tune the WF of the PCC based on the multi-objective particle swarm optimization (MOPSO) algorithm. A Pareto dominance concept is used for the MOPSO to find the optimal WF values for the PCC, comparing parameters of root-mean-square error of the stator tracking currents. The proposed method offers a systematic approach to the WF selection, with an algorithm of easy implementation with direct control over the size of the search space and the speed of convergence. Simulation and experimental results in steady-state and transient conditions are provided to validate the proposed offline tuning procedure of the PCC of a six-phase induction machine. The improvements of RMSE can be more than $500 \%$ for $x-y$ subspace, with minor effect in $\alpha-\beta$ subspace. Finally, the proposed method is extended to a more complex cost function, and the results are compared with an ANN approach.
\end{abstract}

Index Terms-Model predictive control, multiphase induction machine, pareto optimal, particle swarm optimization, stator currents control, weighting factor.

This work was supported by the Paraguayan Government through the CONACYT grant POSG16-05 and the PRONII program. This work was also supported in part by the Spanish State Research Agency (AEI) under project PID2019-105612RB-I00/AEI/10.13039/501100011033. J. Rodriguez acknowledges the support of ANID through projects FB0008, ACT192013 and 1210208 .

Corresponding author: Jorge Rodas.

H. Fretes, J. Rodas V. Gomez, N. Gomez are with the Laboratory of Power and Control Systems, Facultad de Ingeniería, Universidad Nacional de Asunción, Paraguay (e-mail: hectorfretesac@gmail.com, jrodas@ing.una.py, sebasg7@gmail.com,ni_co182@hotmail.com).

J. Doval-Gandoy is with the CINTECX, Universidade de Vigo, Applied Power Electronics Technology research group (APET), 36310 Vigo, Spain (e-mail: jdoval@uvigo.es)

M. Novak is with the AAU Energy, Aalborg University, Denmark (e-mail: nov@energy.aau.dk).

J. Rodriguez, is with Universidad Andres Bello, Chile (e-mail: jose.rodriguez@unab.cl).

T. Dragičević is with the Department of Electrical Engineering, Technical University of Denmark, Denmark (e-mail: tomdr@elektro.dtu.dk).

\section{INTRODUCTION}

$\mathbf{M}$ ULTIPHASE machines can be found today in several commercial products such as wind turbines, electric buses, high-speed elevators, ships, among others [1]. The main advantage of this topology compared to the conventional three-phase one is its higher reliability with intrinsic fault-tolerance capability [2]. The proposal of new control techniques is still an interesting research topic in the multiphase field. Therefore, a huge number of control strategies have been proposed for multiphase machines, from linear to non-linear techniques [3]. Finite-set model predictive control (FS-MPC) is a non-linear control technique that does not need linearizations or mean values. It works with instantaneous values, which is a simplification. FS-MPC as predictive current control (PCC) has been one of the most popular choices in the last decade for regulating the stator currents of multiphase machines [4], [5]. However, for multiphase machines, it is necessary to control not only the $\alpha-\beta$ stator currents (related to the torque production) but also those in the secondary $x-y$ subspace, which are related to the multiphase machine losses [6]. Consequently, the extension of classical PCC of the three-phase to the multiphase case is not straightforward.

PCC of multiphase machines has been proposed for the first time in [7]. Since then, many improvements for the PCC methods have been proposed for the same system, mostly to solve some issues related to FS-MPC such as high computational burden [8], mathematical model improvement [9], fixed-switching frequency [10], among others. Other contributions more related to multiphase machines were performed for $x-y$ current reduction [11], [12], predictive torque control [13] and post-fault operation [14]. In all the before-mentioned FS-MPC approaches, the cost function (CF) is used to determine the desired behaviour of the systems. In multi-objective FS-MPC, the $\mathrm{CF}$ includes the weighting factor (WF), the value of which has been usually determined by trial and error procedure for multiphase machine systems providing a trade-off among the variables of interest [15].

The proper tuning of WFs is of paramount importance to obtain an optimal control performance. For that reason, it 
is still an open problem, and several approaches have been proposed to tackle this issue. In [16] some guidelines are summarized for CFs without WF, with CFs with secondary terms, and with CFs with equally essential terms. This guideline is based on the heuristic strategy, and it is an extension of [17]. Although the proposed guideline can help us reduce the number of tuning trials, it still depends on the empirical procedures. Recently, an artificial neural network (ANN) approach is employed to select the WFs automatically [18]. Nonetheless, numerous simulations or experiments are still inevitable to extract the sample data. In [19] a summary of the latest WF tuning techniques for the most used power electronic converters and electric motor drives are presented. However, according to the best of the authors' knowledge, a proper tuning procedure for the PCC of multiphase machines is still missing. In [20] a WF guideline for a five-phase induction machine (IM) has been proposed. However, the proposal is still a heuristic strategy, and the obtained WF values are not the same for all multiphase IMs [15].

In this paper, an optimal tuning procedure is proposed based on multi-objective particle swarm optimization (MOPSO) algorithm for a six-phase IM for the first time. A remarkable contribution of this work is that the algorithm can find optimal WF values, achieving an optimal trade-off among the user-defined figure of merits such as root-mean-squared (RMS) tracking error of $\alpha-\beta$ and $x-y$ stator currents. Moreover, the concept of Pareto optimality is also combined in this paper with the MOPSO algorithm to find sets of optimal calibrations of the WFs parameters quickly. The users can choose the trade-off according to their needs. For general applications, the combination of MOPSO with Pareto optimality gives the following advantages compared to heuristic methods: simple implementation, direct control over the size of the search space and convergence, low time and space complexity in comparison to evolutionary algorithms commonly used in multi-objective optimization.

The rest of the paper is organized as follows. The mathematical model of the two 2-level voltage source inverter (2L-VSI) and electric drive systems are explained in Section II. PCC technique is also introduced in the same section. In Section III the proposed MOPSO algorithm is described. An analysis based on simulation and experimental results is presented in Section IV. Finally, conclusions and future trends are summarised in Section V.

\section{PRELiminaries}

\section{A. Six-phase IM and 2L-VSI model}

The analyzing system consists of an asymmetrical six-phase IM with two isolated neutral points, fed by 2L-VSI, shown in Fig. 1. After using the vector space decomposition (VSD) approach [21], the decoupling transformation $\mathbf{T}$ gives $\alpha-\beta$ subspace, which is related to flux/torque producing components and loss-producing $x-y$ subspace and a zero-sequence subspace. Then, by using an amplitude invariant criterion, $\mathbf{T}$ is defined as follows:

$$
\mathbf{T}=\frac{1}{3}\left[\begin{array}{cccccc}
1 & \frac{\sqrt{3}}{2} & -\frac{1}{2} & -\frac{\sqrt{3}}{2} & -\frac{1}{2} & 0 \\
0 & \frac{1}{2} & \frac{\sqrt{3}}{2} & \frac{1}{2} & -\frac{\sqrt{3}}{2} & -1 \\
1 & -\frac{\sqrt{3}}{2} & -\frac{1}{2} & \frac{\sqrt{3}}{2} & -\frac{1}{2} & 0 \\
0 & \frac{1}{2} & -\frac{\sqrt{3}}{2} & \frac{1}{2} & \frac{\sqrt{3}}{2} & -1 \\
1 & 0 & 1 & 0 & 1 & 0 \\
0 & 1 & 0 & 1 & 0 & 1
\end{array}\right] .
$$

Usually, the discrete model of the system in state-space representation is represented as follows:

$$
\begin{aligned}
\mathbf{x}_{k+1} & =\mathbf{A} \mathbf{x}_{k}+\mathbf{B} \mathbf{u}_{k}+\mathbf{n}_{k} \\
\mathbf{y}_{k} & =\mathbf{C} \mathbf{x}_{k}+\mathbf{m}_{k}
\end{aligned}
$$

where stator and rotor current are included in the state vector $\mathbf{x}_{k}$

$$
\mathbf{x}_{k}=\left[i_{s \alpha(k)}, i_{s \beta(k)}, i_{s x(k)}, i_{s y(k)}, i_{r \alpha(k)}, i_{r \beta(k)}\right]^{T}
$$

while the stator voltages represent the input vector:

$$
\mathbf{u}_{k}=\left[u_{s \alpha(k)}, u_{s \beta(k)}, u_{s x(k)}, u_{s y(k)}\right]^{T}
$$

and the stator currents are included the output vector:

$$
\mathbf{y}_{k}=\left[i_{s \alpha(k)}, i_{s \beta(k)}, i_{s x(k)}, i_{s y(k)}\right]^{T}
$$

and $\mathbf{n}_{k}$ is the process noise and $\mathbf{m}_{k}$ the measurement noise. The stator voltages, represented by (2), have a discrete nature (Fig. 2) due to the 2L-VSI model, these vectors are obtained by applying the transformation $\mathbf{T}$ to the phase voltages for each possible state of the converter, with a total number of $2^{6}=64$ switching possible states defined by the six-legs. Among the 64 possibilities, only 49 different vectors ( 48 vectors +1 null vector) are considered in the $\alpha-\beta$ and $x-y$ subspaces, due to the redundancy.

$$
\mathbf{u}_{k}=V_{\mathrm{dc}} \mathbf{T} \mathbf{M}
$$

where the gating signals are $\mathbf{S}=\left[S_{a}, S_{b}, S_{c}, S_{d}, S_{e}, S_{f}\right]$, being $S_{i} \in\{0,1\}, V_{\mathrm{dc}}$ is the dc-bus voltage and the $2 \mathrm{~L}-\mathrm{VSI}$ model is:

$$
\mathbf{M}=\frac{1}{3}\left[\begin{array}{cccccc}
2 & 0 & -1 & 0 & -1 & 0 \\
0 & 2 & 0 & -1 & 0 & -1 \\
-1 & 0 & 2 & 0 & -1 & 0 \\
0 & -1 & 0 & 2 & 0 & -1 \\
-1 & 0 & -1 & 0 & 2 & 0 \\
0 & -1 & 0 & -1 & 0 & 2
\end{array}\right] \mathbf{S}^{T} \text {. }
$$

The matrices $\mathbf{A}, \mathbf{B}$ are defined as follows:

$$
\mathbf{A}=\left[\begin{array}{cccccc}
a_{11} & a_{12} & 0 & 0 & a_{15} & a_{16} \\
a_{21} & a_{22} & 0 & 0 & a_{25} & a_{26} \\
0 & 0 & a_{33} & 0 & 0 & 0 \\
0 & 0 & 0 & a_{44} & 0 & 0 \\
a_{51} & a_{52} & 0 & 0 & a_{55} & a_{56} \\
a_{61} & a_{62} & 0 & 0 & a_{65} & a_{66}
\end{array}\right]
$$




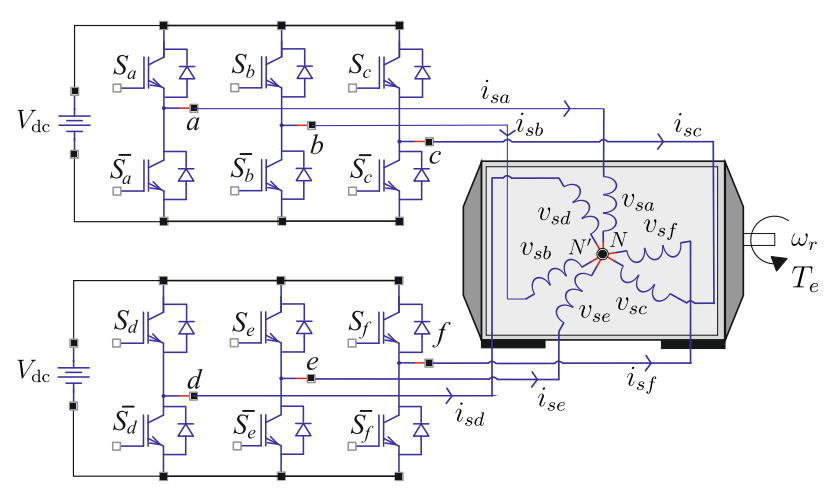

Fig. 1. Schematic diagram of the 2L-VSI.

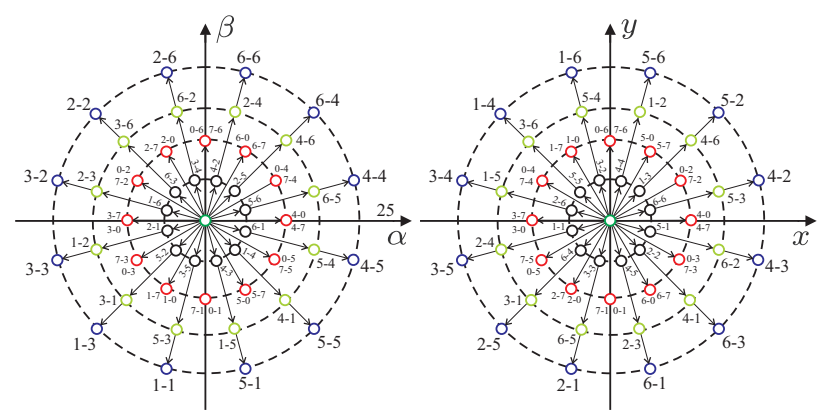

Fig. 2. Projections of the voltage vectors in the $\alpha-\beta$ (left) and $x-y$ (right) subspaces for a six-phase IM obtained using VSD approach [21]. The number that defines each voltage is identified by two octal numbers corresponding to the binary numbers $\left[S_{a} S_{b} S_{c}\right]$ and $\left[S_{d} S_{e} S_{f}\right]$.

$$
\mathbf{B}=\left[\begin{array}{cccc}
b_{1} & 0 & 0 & 0 \\
0 & b_{1} & 0 & 0 \\
0 & 0 & b_{2} & 0 \\
0 & 0 & 0 & b_{2} \\
b_{3} & 0 & 0 & 0 \\
0 & b_{3} & 0 & 0
\end{array}\right]
$$

where:

$$
\begin{array}{ll}
a_{11}=a_{22}=1-T_{s} c_{2} R_{s} & a_{55}=a_{66}=1-T_{s} c_{5} R_{r} \\
a_{15}=a_{26}=T_{s} c_{4} R_{r} & a_{33}=a_{44}=1-T_{s} c_{3} R_{s} \\
a_{16}=-a_{25}=T_{s} c_{4} L_{r} \omega_{r(k)} & a_{51}=a_{62}=-T_{s} c_{4} R_{s} \\
a_{52}=-a_{61}=-T_{s} c_{5} L_{m} \omega_{r(k)} & b_{1}=T_{s} c_{2} \\
a_{56}=-a_{65}=-c_{5} \omega_{r(k)} T_{s} L_{r} & b_{2}=T_{s} c_{3} \\
a_{12}=-a_{21}=T_{s} c_{4} L_{m} \omega_{r(k)} & b_{3}=-T_{s} c_{4}
\end{array}
$$

$T_{s}$ is the sampling time and $c_{1}-c_{5}$ are defined as: $c_{1}=$ $L_{s} L_{r}-L_{m}^{2}, c_{2}=\frac{L_{r}}{c_{1}}, c_{3}=\frac{1}{L_{l s}} c_{4}=\frac{L_{m}}{c_{1}} c_{5}=\frac{L_{s}}{c_{1}}$. The electrical parameters of the system are $R_{s}, R_{r}^{L_{1}}, L_{r}=L_{l r}^{c_{1}}+L_{m}$, $L_{s}=L_{l s}+L_{m}, L_{r}$ and $L_{m}$. The rotor electrical speed $\left(\omega_{r}\right)$ has a relationship with load torque $\left(T_{l}\right)$ and generated torque $\left(T_{e}\right)$ as follows:

$$
J_{m} \dot{\omega}_{r}+B_{m} \omega_{r}=P\left(T_{e}-T_{l}\right)
$$

where $B_{m}$ and $J_{m}$ are the friction and the inertia coefficient, respectively, $P$ is the number of pole pairs and $T_{e}$ is:

$$
T_{e}=3 P M\left(i_{r \beta} i_{s \alpha}-i_{r \alpha} i_{s \beta}\right)
$$

where $M$ is the magnetizing inductance.

\section{B. PCC of a Six-Phase IM}

FS-MPC uses the model of the system to analyze its future behaviour. In this case, the PCC uses the discrete model of the system (2) to predict (at time $k$ ) the $k+1$ six-phase IM's stator currents. To consider the delay compensation, $\hat{\mathbf{x}}_{k+2}$ is obtained iteratively using the predictive model. The unmeasured rotor currents are estimated by using the Kalman filter [9], [22]. For each possible state of the VSI, a cost function $J$ is calculated. This cost function is defined by:

$$
J=\left|e_{\alpha \beta}\right|^{2}+\lambda_{x y}\left|e_{x y}\right|^{2}
$$

where:

$$
\begin{aligned}
& e_{\alpha \beta}=i_{s \alpha \beta[k+1]}^{*}-i_{s \alpha \beta[k+1]} \\
& e_{x y}=i_{s x y[k+1]}^{*}-i_{s x y[k+1]} .
\end{aligned}
$$

The control objective is to select the VSI state that minimizes $J$. In the particular cost function chosen, the WF parameter $\lambda_{x y}$ needs to be tuned. Note that it is not strictly necessary to normalize the cost function due to the two terms being of the same nature. Normalization makes sense when the CF deals with different variables (e.g. torque and flux) that also have very different numerical values [16].

\section{PROPOSED WF DESIGN}

To find the best values for the WF parameter $\lambda_{x y}$, the RMS tracking error of the $\alpha-\beta$ and $x-y$ stator currents are evaluated and used as performance indicators or objectives, making this multiple objective optimization problems. ANN has been used along with the weighted sum of goals as an approach to obtain the WF parameters by [18]. However, the control designer still has limited control over the trade-off among the objectives. Moreover, this control is also not intuitive. The ANN method consists of obtaining the different responses of the system for a range of WF values and then obtaining the minimum with another method, i.e., the Matlab min function. The location of the minimum value depends on the relationship between the objective weights, which the user defines manually. Alternatively, by using the Pareto optimally concept, the control designer can choose the best set of $\lambda_{x y}$ with knowledge of the behaviour of this trade-off. Among the various multi-objective algorithms that use the Pareto optimality concept, two algorithms widely used in different applications are multi-objective particle swarm optimization (MOPSO) and non-dominated sorting genetic algorithm (NSGA-II). These algorithms have proved to be similar in terms of performance. In [23], both algorithms' effectiveness was demonstrated with various standard test problems, concluding that the NSGA-II is more accurate while the MOPSO is faster. In [24], again, both algorithms are used to optimize the sizing of hybrid energy storage systems, with the same conclusion of the previously cited work. Furthermore, in [25] both algorithms are compared in a water pump system design, obtaining better results in terms of efficiency of the pump with the MOPSO algorithm. In this work, the use MOPSO algorithm for two reasons. First, due to its simplicity. Second, because it offers an easy way to control the trade-off 
between speed of convergence and depth of exploration, as presented in [26].

\section{A. Particle Swarm Optimization (PSO) Algorithm}

The PSO algorithm is a stochastic population-based algorithm first proposed in [27], offering a way of trading off the speed of convergence and the time needed for the exploration. In the PSO algorithm, all of the particles in the swarm move in a search space defined by the independent variables of the problem. The latter corresponds to the WF $\lambda_{x y}$. When a particle moves, the algorithm evaluates the parameters taken by the corresponding particle according to a Fitness function $\mathbf{f}\left(\mathbf{p}_{n}\right)$. Usually, the objective of the PSO algorithm is to minimize $\mathbf{f}\left(\mathbf{p}_{n}\right)$. Each particle $\mathbf{p}_{n}$ in the swarm of $N$ particles has a velocity of $\mathbf{v}_{n}$, which determines its location in the search space for the next iteration $j+1$ [26]:

$$
\mathbf{p}_{n[j+1]}=\mathbf{p}_{n[j]}+\chi \mathbf{v}_{n[j]}+\epsilon_{[j]}
$$

where $\chi \in[0,1]$ is a constraint value used to limit the velocity of each particle and $\epsilon$ is a vector with random uniformly distributed components in the range $[-1,1]$. The latter allows the algorithm to increase the range of exploration of the swarm to avoid local minima, by deviating the particle from the path defined by $\mathbf{v}_{n}$. The velocity $\mathbf{v}_{n}$ of the particles is modified in each iteration so that these move towards the best position found by the particle. The Personal guide $\mathbf{P} \mathbf{b}_{n}$ (or Personal best), and the Global guide Gb (Global best, i.e., the best position found by the whole swarm) achieve an exchange of information among the particles. All of this is accomplished by updating the velocity vector by using the following equation:

$$
\mathbf{v}_{n[j+1]}=\hat{w} \mathbf{v}_{n[j]}+r_{1} \hat{c}_{1}\left(\mathbf{P}_{n}-\mathbf{p}_{n[j]}\right)+r_{2} \hat{c}_{2}\left(\mathbf{G b}-\mathbf{p}_{n[j]}\right)
$$

where $r_{1}$ and $r_{2}$ are random evenly distributed numbers in the range of $[0,1], \hat{c}_{1}$ and $\hat{c}_{2}$ are control factors that establish the influence of global and personal knowledge. Finally, $\hat{w}$ is a factor of inertia, which controls the trade-off between convergence and explorability of the search space. These parameters are selected by trial and error procedure, using the trade-off between convergence and explorability as the criterion, and follow a set of simple rules:

- To increase convergence, $\hat{c}_{1}<\hat{c}_{2}, \hat{w} \rightarrow 0, \chi \rightarrow 1$.

- To increase explorability, $\hat{c}_{1}>\hat{c}_{2}, \hat{w} \rightarrow 1, \chi \rightarrow 0$.

Note that these parameters belong to the PSO algorithm and are directly tied to the time and space complexity of the algorithm and the number of points of the search space to be analyzed. Thus, they are defined by time constraints and the desired explorability of the search space.

\section{B. Pareto Optimal Principle}

Since the PSO is based on a simple concept and is both fast and computationally inexpensive, it has been extended to handle multi-objective optimisation problems. The majority of MOPSO algorithms share the same basic approach-a swarm of a certain number of agents is initialised randomly. That number will remain constant until the end of the run.
In optimisation problems with multiple objectives, a set of $D$ objectives have to be optimised. These $D$ objectives $\left(o_{i}\right)$ depend on a vector $\mathbf{p}$ of $K$ decision variables:

$$
o_{i}=\mathbf{f}(\mathbf{p}) \quad \forall i=1,2,3, \cdots, D .
$$

The main issue with multi-objective optimization problems is that there is not an unique solution, rather than a set of solutions when all the objective variables are taken into account. One approach that can be used is to make a single fitness function equal to a weighted sum of the objectives [28]. In this case, it is difficult to control the trade-off relationship between the different objectives and there is a high probability of falling into local minima, making it difficult to obtain optimal values. However, this set of solutions can be determined using the Pareto optimal principle. According to the Pareto optimal principle [29], a vector $p_{1}$ strictly dominates another one $p_{2}$ (denoted $p_{1} \prec p_{2}$ ) if:

$$
f_{i}\left(p_{1}\right)<f_{i}\left(p_{2}\right) \quad \forall i=1,2,3, \cdots, D,
$$

and $p_{1}$ weakly dominates $p_{2}$ (denoted $p_{1} \preceq p_{2}$ ) if:

$$
f_{i}\left(p_{1}\right) \leq f_{i}\left(p_{2}\right) \quad \forall i=1,2,3, \cdots, D .
$$

The Pareto front is the set of all non-dominated solutions, while the Pareto optimal is a set of vectors that correspond to the Pareto front. In a multi-objective optimisation problem, the target is usually to find a well-distributed Pareto front. In Fig. 3 a two-dimensional Pareto front is observed in the performance space of the particles $\mathbf{p}$. The performance space is such that each axis corresponds to an objective variable $f_{i}(\mathbf{p})$ (for this case $i=1,2$ ). The green points correspond to the non-dominated particles of an optimisation problem, while the blue points are dominated particles. Note that the $\mathbf{p}$ particles are of $K$ dimensions. The dominance of one particle over another means that a dominant particle has all its components in the performance space (that is, its objective variables) with less or equal value than the respective components of another particle in the same space. These conditions make up the Pareto Optimal Principle. Therefore, a Pareto front in the performance space corresponds to particles in said space that present the best performances. This principle is key to effective multi-objective optimisation. Consequently, we can obtain a set of values that minimises objective variables. We can pick a final solution from this set through design criteria, such as prioritising one objective variable and setting a performance metric, among other possibilities. In this paper, the RMS tracking errors of the $\alpha-\beta$ and $x-y$ stator currents are considered as objective variables and $\lambda_{x y}$ is the decision variable, as stated in (19).

$$
\mathbf{f}(\mathbf{p})=\mathbf{o}=\left[\begin{array}{l}
\mathrm{RMSE}_{\alpha \beta} \\
\operatorname{RMSE}_{x y}
\end{array}\right]=\left[\begin{array}{l}
f_{1}\left(\lambda_{x y}\right) \\
f_{2}\left(\lambda_{x y}\right)
\end{array}\right]
$$

RMSE is defined as:

$$
\begin{aligned}
\operatorname{RMSE}_{\alpha \beta} & =\sqrt{\mathrm{RMSE}_{\alpha}^{2}+\mathrm{RMSE}_{\beta}^{2}} \\
\mathrm{RMSE}_{x y} & =\sqrt{\mathrm{RMSE}_{x}^{2}+\mathrm{RMSE}_{y}^{2}}
\end{aligned}
$$




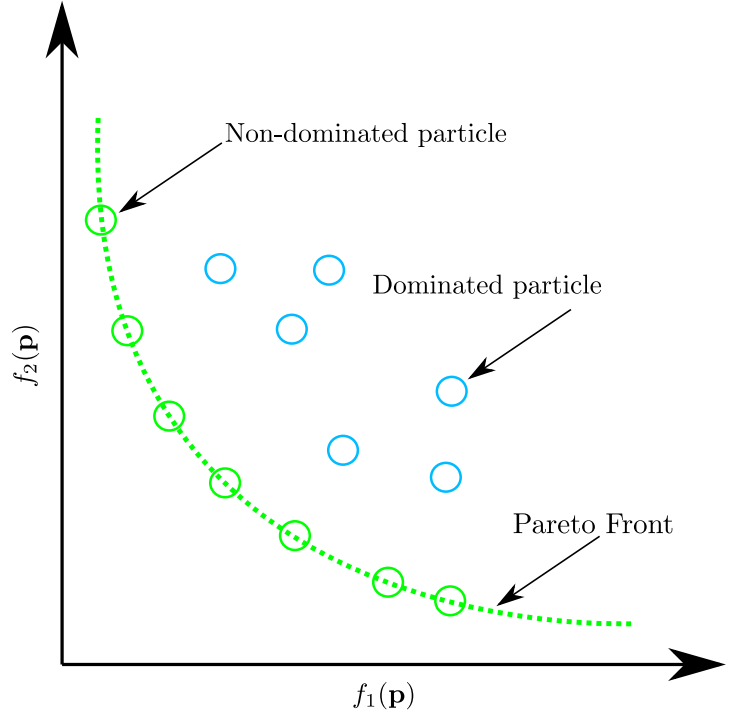

Fig. 3. Example of a Pareto front. The green curve corresponds to the Pareto front. Green circles are non-dominated particles, these lie on the Pareto front. Blue circles are dominated particles.

$$
\operatorname{RMSE}_{j}=\sqrt{\frac{1}{N} \sum_{k=1}^{N}\left\|i_{s j}{ }^{*}(k)-i_{s j}(k)\right\|^{2}}
$$

where $\{j=\alpha, \beta, x, y\}$ and $N$ represents the total number of analyzed samples. All values are obtained using the mathematical model of the electric motor and current controller described in the previous sections. The main difficulty of using the PSO for multiple objective problems is how to choose the best guides. As with other multiple objective algorithms, the concept of Pareto optimal is used so that the controller designer can choose a convenient solution from the Pareto front. This approach has shown good results in previous works in [29] and [30]. As a consequence, this method has been chosen for this paper due to its simplicity.

During the implementation of the MOPSO, a repository $\mathbf{R}_{\mathbf{p}}$ is used to store all of the non-dominated particles up to the current iteration. This repository is updated with every iteration, tending to become the Pareto front of the problem. The updating method is executing as follows. First, when a particle finds a new non-dominated position, the MOPSO algorithm checks if the particle dominates its previous personal guide or any element from $\mathbf{R}_{\mathbf{p}}$. Then, the MOPSO removes them if that is the case, adding the new particle to $\mathbf{R}_{\mathbf{p}}$. If the previous personal best is also non dominated, the unique personal best is chosen randomly between the previous one and the new particle. The selection of the global guide for each particle $\mathbf{R}_{\mathbf{p}}$ is based on "PROB" method described in [29] for selecting the best global guides.

By using the Pareto Front approach, a set of possible solutions to the optimisation problem is obtained, which allows to observe the variation of the current tracking performance in both $\alpha-\beta$ and $x-y$ spaces caused by the variation of $\lambda_{x y}$. The controller's designer can then pick a value of $\lambda_{x y}$ based on design criteria, such as limiting the RMSE in both spaces to certain values, minimizing a mathematical

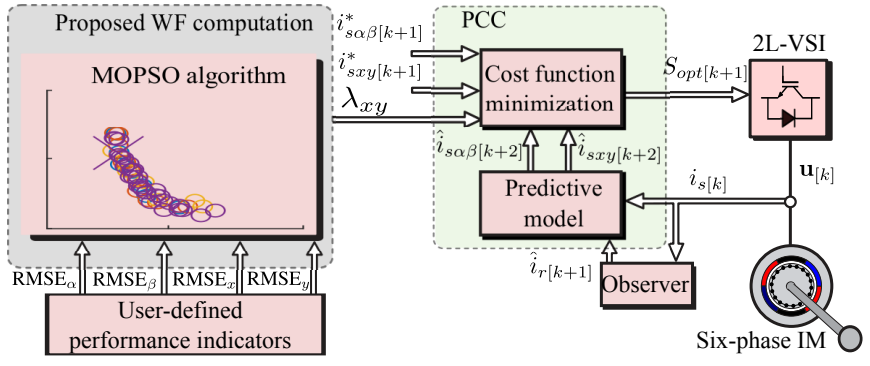

Fig. 4. PCC structure including the proposed WF computation based on MOPSO algorithm.

relationship between the RMSE in both spaces, among others.

\section{Simulation AND EXPERIMENTAl RESUlts}

To validate the proposed WF tune procedure, the MOPSO is first simulated by using a custom-designed Matlab/Simulink file and the following parameters of a real six-phase IM: $R_{s}=6.7 \Omega, R_{r}=7 \Omega, L_{l s}=5.85 \mathrm{mH}, L_{l r}=55.7 \mathrm{mH}$, $L_{m}=708.5 \mathrm{mH}$ and $J_{m}=0.07 \mathrm{Kg} \cdot \mathrm{m}^{2} / \mathrm{s}^{2}$. PCC structure and the experimental setup is shown in Fig. 4 and Fig. 5, respectively. The MOPSO parameters are $\hat{c}_{1}=1, \hat{c}_{2}=0.9$, $\chi=1$ and $\hat{w}=0.6$; and are kept constant for every test condition, as they are related to the search space and not the machine's operating conditions. Three rotor speed references $\left(\omega_{r}^{*}\right) 5001 / \mathrm{min}, 10001 / \mathrm{min}$ and $15001 / \mathrm{min}$ were considered, while the $d-q$ stator current references are $i_{d}^{*}=1 \mathrm{~A}$ and $i_{q}^{*}=1$ A. Three sampling frequencies $\left(f_{s}\right) 8 \mathrm{kHz}$, $10 \mathrm{kHz}$, and $16 \mathrm{kHz}$ were also considered. For each $\omega_{r}^{*}$ and $f_{s}$, four calibrations were made, with $N=10$ particles and 25 generations. However, for the $15001 / \mathrm{min}$ case, an extra pair of the calibration was made, with 50 generations each, to verify if a higher number of generations can give better results. The obtained Pareto fronts for $f_{s}=10 \mathrm{kHz}$ and their respective optimal values can be seen in Fig. 6. Note that the vertical axis scale is different (zoomed) from the scale of the horizontal axis. A total of four Pareto fronts are presented in each figure, one for each calibration, distinguished by colors. The circles correspond to points of the Pareto fronts. Any of these points are optimal values that can be selected according to the designer's criteria. For this paper, the selected points are chosen by minimizing the following expression:

$$
\eta=\sqrt{\operatorname{RMSE}_{\alpha \beta}^{2}+\mathrm{RMSE}_{x y}^{2}}
$$

Points that meet this criterion for each calibration are shown in the figures, with their corresponding values of $\lambda_{x y}$. The similar point's location for each calibration offers the repetitiveness of the proposed method.

Then, experimental validation was made with a $V_{d c}=$ $400 \mathrm{~V}$. For each $\omega_{r}^{*}$ and $f_{s}$, an optimal $\lambda_{x y}$ provided by the MOPSO algorithm (shaded rows in all tables) is chosen and compared with another $\lambda_{x y}$ randomly chosen.

Table I reports the experimental results for $f_{s}=16 \mathrm{kHz}$, and the mentioned three speeds. It shows that when the maximum priority is put on $\alpha-\beta$ subspace by using $\lambda_{x y}=0$, the minimum RMSE is obtained for that 


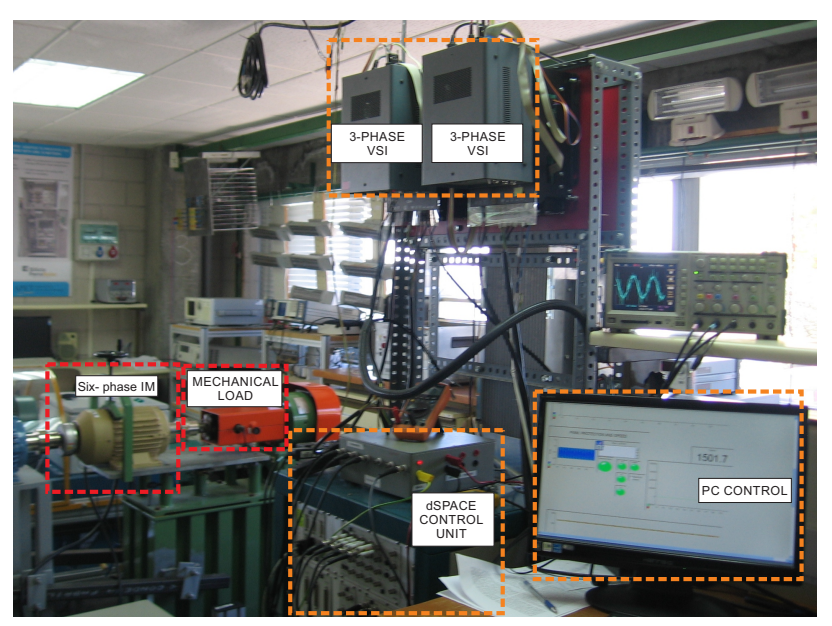

Fig. 5. Block diagram of the test bench including the six-phase IM, the dSPACE platform, the eddy current brake and the six-phase VSI.

TABLE I

STEADY STATE TEST OF STATOR CURRENTS $\alpha-\beta, x-y$, RMSE (A) WITH $f_{s}=16 \mathrm{KHZ}$ AND DIFFERENT $\omega_{r}^{*}$.

\begin{tabular}{|c|c|c|c|c|}
\hline & & $\omega_{r}^{*}=500$ & $1 / \mathrm{min}$ & \\
\hline$\lambda_{x y}$ & $\mathrm{RMSE}_{\alpha}$ & $\mathrm{RMSE}_{\beta}$ & $\mathrm{RMSE}_{x}$ & $\mathrm{RMSE}_{y}$ \\
\hline 0 & 0.0685 & 0.0659 & 3.6544 & 3.6467 \\
\hline 0.0120 & 0.0752 & 0.0740 & 0.4471 & 0.4411 \\
\hline 0.0190 & 0.0850 & 0.0840 & 0.3713 & 0.3683 \\
\hline 0.1 & 0.1100 & 0.1074 & 0.2647 & 0.2658 \\
\hline \multirow[t]{2}{*}{1} & 0.2220 & 0.2207 & 0.1293 & 0.1302 \\
\hline & & $\omega_{r}^{*}=1000$ & $1 / \mathrm{min}$ & \\
\hline$\lambda_{x y}$ & $\mathrm{RMSE}_{\alpha}$ & $\mathrm{RMSE}_{\beta}$ & $\mathrm{RMSE}_{x}$ & $\mathrm{RMSE}_{y}$ \\
\hline 0 & 0.0739 & 0.077091 & 3.5964 & 3.5721 \\
\hline 0.0179 & 0.0961 & 0.0944 & 0.4111 & 0.4108 \\
\hline 0.0196 & 0.0961 & 0.0949 & 0.4025 & 0.3996 \\
\hline 0.1 & 0.1306 & 0.1272 & 0.2898 & 0.2880 \\
\hline \multirow[t]{2}{*}{1} & 0.2648 & 0.2561 & 0.1463 & 0.1474 \\
\hline & & $\omega_{r}^{*}=1500$ & $1 / \mathrm{min}$ & \\
\hline$\lambda_{x y}$ & $\mathrm{RMSE}_{\alpha}$ & $\mathrm{RMSE}_{\beta}$ & $\mathrm{RMSE}_{x}$ & $\mathrm{RMSE}_{y}$ \\
\hline 0 & 0.0812 & 0.0804 & 3.4826 & 3.5658 \\
\hline 0.0161 & 0.0725 & 0.0731 & 0.4253 & 0.4249 \\
\hline 0.0196 & 0.0773 & 0.0764 & 0.4086 & 0.4113 \\
\hline 0.1 & 0.1291 & 0.1261 & 0.3162 & 0.3154 \\
\hline 1 & 0.3013 & 0.2952 & 0.1559 & 0.1562 \\
\hline
\end{tabular}

subspace, and the maximum is obtained for $x-y$ for all rotor speeds. If the WF increases, the $\mathrm{RMSE}_{\alpha \beta}$ increases while the RMSE $x y$ improves. The obtained WF for the MOPSO algorithm shows that with a small value of $\lambda_{x y}$, the RMSE $x y$ improves significantly while $\operatorname{RMSE}_{\alpha \beta}$ hardly increases. Further increasing the value of the WF improves the $\mathrm{RMSE}_{x y}$ with diminishing returns, at the cost of a notable increase of the RMSE ${ }_{\alpha \beta}$. The same conclusions can be done for Table II and Table III, which report the experimental results for $f_{s}=10 \mathrm{kHz}$ and $f_{s}=8 \mathrm{kHz}$, respectively. Note that the idea behind testing at different values of $\omega_{r}^{*}$ and the sampling frequency is to test the proposed WF design method under different conditions. This is done because the final application of the machine defines $\omega_{r}^{*}$, and the sampling

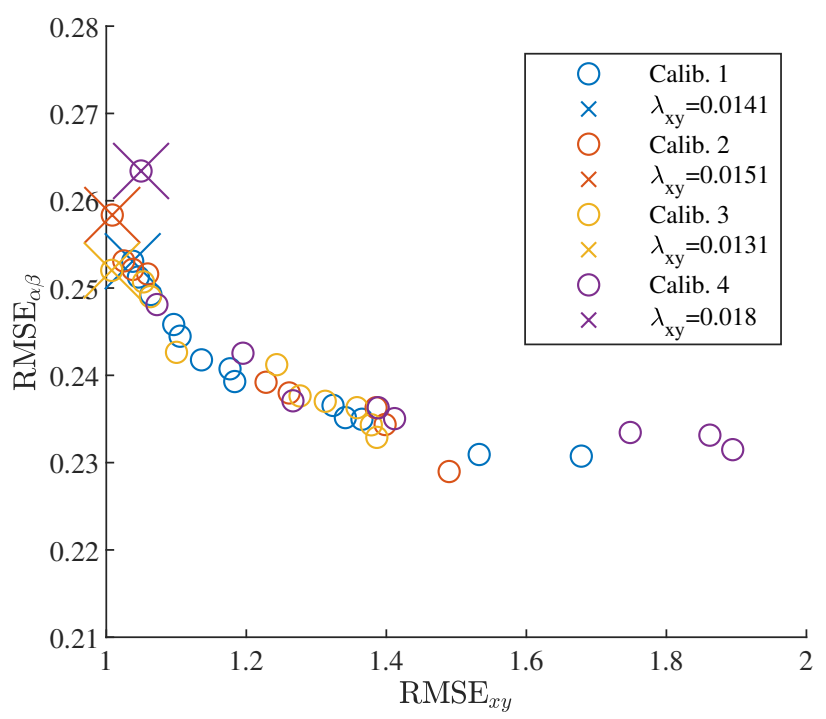

(a)

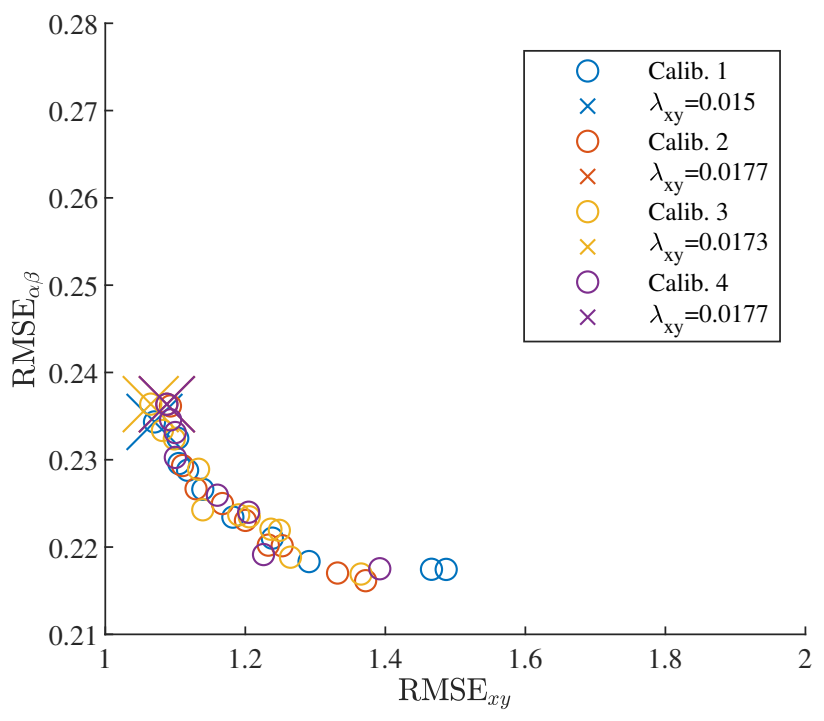

(b)

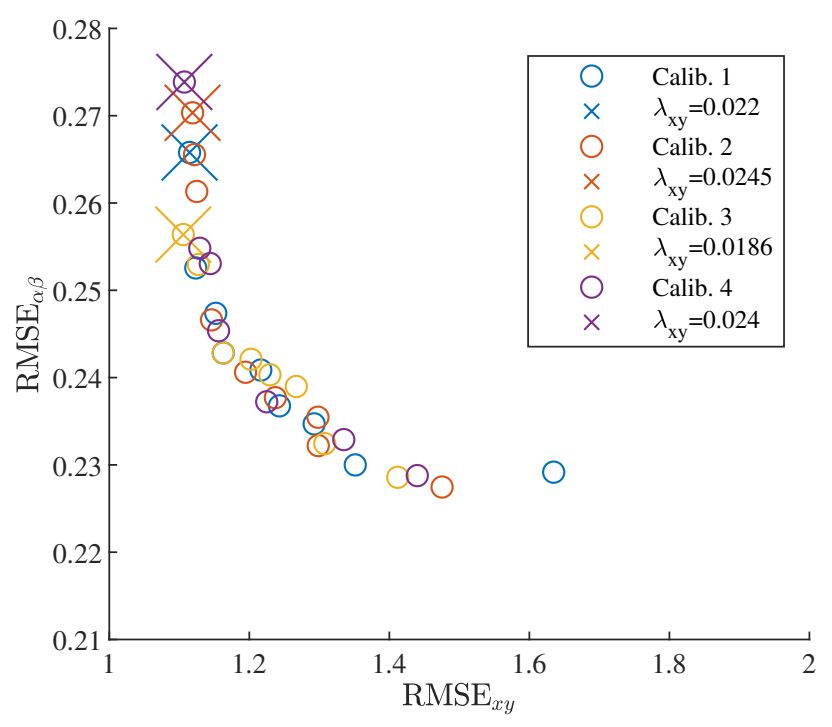

(c)

Fig. 6. Pareto fronts obtained with $f_{s}=10 \mathrm{kHz}$ for (a) $\omega_{r}^{*}=5001 / \mathrm{min}$, (b) $\omega_{r}^{*}=10001 / \mathrm{min}$, and (c) $\omega_{r}^{*}=15001 / \mathrm{min}$. 
TABLE II

STEADY STATE TEST OF STATOR CURRENTS $\alpha-\beta, x-y$, RMSE (A) WITH $f_{s}=10 \mathrm{KHZ}$ AND DIFFERENT $\omega_{r}^{*}$.

\begin{tabular}{|c|c|c|c|c|}
\hline & & $\omega_{r}^{*}=500$ & $1 / \mathrm{min}$ & \\
\hline$\lambda_{x y}$ & $\mathrm{RMSE}_{\alpha}$ & $\mathrm{RMSE}_{\beta}$ & $\operatorname{RMSE}_{x}$ & $\mathrm{RMSE}_{y}$ \\
\hline 0 & 0.1049 & 0.0936 & 3.9747 & 3.9391 \\
\hline 0.0131 & 0.1135 & 0.1126 & 0.6171 & 0.6138 \\
\hline 0.0180 & 0.1230 & 0.1218 & 0.5294 & 0.5305 \\
\hline 0.1 & 0.1594 & 0.1587 & 0.3826 & 0.3759 \\
\hline \multirow[t]{2}{*}{1} & 0.3114 & 0.3068 & 0.1882 & 0.1884 \\
\hline & & $\omega_{r}^{*}=1000$ & $1 / \mathrm{min}$ & \\
\hline$\lambda_{x y}$ & $\mathrm{RMSE}_{\alpha}$ & $\operatorname{RMSE}_{\beta}$ & $\mathrm{RMSE}_{x}$ & $\mathrm{RMSE}_{y}$ \\
\hline 0 & 0.1056 & 0.1088 & 4.0768 & 4.0130 \\
\hline 0.0150 & 0.1215 & 0.1208 & 0.6409 & 0.6432 \\
\hline 0.0177 & 0.1265 & 0.1260 & 0.6000 & 0.6002 \\
\hline 0.1 & 0.1929 & 0.1919 & 0.4199 & 0.4187 \\
\hline \multirow[t]{2}{*}{1} & 0.3678 & 0.3698 & 0.2017 & 0.2005 \\
\hline & & $\omega_{r}^{*}=1500$ & $1 / \mathrm{min}$ & \\
\hline$\lambda_{x y}$ & $\mathrm{RMSE}_{\alpha}$ & $\operatorname{RMSE}_{\beta}$ & $\mathrm{RMSE}_{x}$ & $\mathrm{RMSE}_{y}$ \\
\hline$\overline{0}$ & 0.1462 & $\overline{0.1519}$ & $\overline{4.0806}$ & 4.0239 \\
\hline 0.0186 & 0.1110 & 0.1125 & 0.6344 & 0.6366 \\
\hline 0.0245 & 0.1173 & 0.1178 & 0.6019 & 0.6067 \\
\hline 0.1 & 0.1980 & 0.1976 & 0.4792 & 0.4777 \\
\hline 1 & 0.4484 & 0.4540 & 0.2187 & 0.2170 \\
\hline
\end{tabular}

frequency is ultimately defined by the available hardware, the control scheme and its implementation.

According also to Table I, the best performance is obtained for $\omega_{r}^{*}=5001 / \mathrm{min}$. This result is also consistent since the relationship between $f_{s}=16 \mathrm{kHz}$ and the frequency of the fundamental component is higher than in the other cases, so the PCC is more efficient. The same analysis can be done if the results of Tables I, II, and III are compared at the same speed. As expected, for a given speed, the results of Table III are worse than those of Table II, and these are worse than those of Table I. The latter is because, at higher sampling frequencies, higher switching frequencies are achievable, which ultimately reduces the current tracking error. For higher WF tested and the highest rotor speed, at $10 \mathrm{kHz}, \mathrm{PCC}$ becomes unstable. For $8 \mathrm{kHz}$, the PCC does not work for any WF $\lambda_{x y}$ values at $15001 / \mathrm{min}$.

The reference and measured currents for $\omega_{r}^{*}=10001 / \mathrm{min}$ and $f_{s}=10 \mathrm{kHz}$, with a value obtained by the MOPSO algorithm are plotted in Fig. 7 (b), which shows the best compromise between $\alpha-\beta$ current ripple and $x-y$ currents compared to the extreme cases when $x-y$ current is ignored in the $\mathrm{CF}$, thus $\lambda_{x y}=0$, and when both errors have the same weight, thus $\lambda_{x y}=1$. We can state the latter from Table II, where $\lambda_{x y}=0.0177$ gives the best performance for $\omega_{r}^{*}=10001 / \mathrm{min}$. Fig. 8 shows the waveforms for this $\lambda_{x y}$. Table IV contains the THD for the different values of $\lambda_{x y}$ that were tested. Similar figures were obtained for other sampling frequencies, and they were not included for the sake of conciseness.

As the WF $\lambda_{x y}$ increases, the control effort on the $x-y$ subspace variables increases while the control effort on the $\alpha-\beta$ subspace variables decreases. As shown in Tables I, II, and III, the latter entails that the RMSE decreases for variables
TABLE III

STEADY STATE TEST OF STATOR CURRENTS $\alpha-\beta, x-y$, RMSE (A) WITH $f_{s}=8 \mathrm{KHZ}$ AND DIFFERENT $\omega_{r}^{*}$.

\begin{tabular}{ccccc}
\hline & & $\omega_{r}^{*}=500$ & $1 / m i n$ & \\
\hline$\lambda_{x y}$ & $\mathrm{RMSE}_{\alpha}$ & $\mathrm{RMSE}_{\beta}$ & $\mathrm{RMSE}_{x}$ & $\mathrm{RMSE}_{y}$ \\
\hline \hline 0 & 0.1275 & 0.1236 & 4.2003 & 4.154 \\
\hline 0.0172 & 0.1512 & 0.1505 & 0.6212 & 0.6231 \\
\hline 0.0231 & 0.1576 & 0.1569 & 0.5881 & 0.5877 \\
\hline 0.1 & 0.1936 & 0.1938 & 0.4507 & 0.4512 \\
\hline 1 & 0.3703 & 0.3741 & 0.2357 & 0.2340 \\
\hline \hline & & $\omega_{r}^{*}=1000$ & $1 / \mathrm{min}$ & \\
\hline$\lambda_{x y}$ & $\mathrm{RMSE}_{\alpha}$ & $\mathrm{RMSE}_{\beta}$ & $\mathrm{RMSE}_{x}$ & $\mathrm{RMSE}_{y}$ \\
\hline \hline 0 & 0.1458 & 0.1498 & 4.4836 & 4.4340 \\
\hline 0.0186 & 0.1608 & 0.1609 & 0.7230 & 0.7299 \\
\hline 0.0241 & 0.1701 & 0.1680 & 0.6773 & 0.6721 \\
\hline 0.1 & 0.2282 & 0.2286 & 0.4921 & 0.4879 \\
\hline 1 & 0.4330 & 0.4392 & 0.2514 & 0.2474 \\
\hline
\end{tabular}

in the $x-y$ subspace while it increases for variables related to the $\alpha-\beta$ subspace. This more significant control effort in the $x-y$ subspace also affects the reference tracking error. In this sense, if the tracking error of the variables in the $\alpha-\beta$ subspace, variables related to torque and flux, worsens, the six-phase IM torque will be affected. Suppose the current component associated with torque, namely $i_{q}$, cannot reach the setpoint. In that case, the six-phase IM's ability to reach the torque value set by the reference will be reduced. On the other hand, if the current component related to the flux, namely $i_{d}$, cannot reach the setpoint, the field will be weakened and, therefore, the six-phase IM's torque.

To demonstrate this behaviour, the six-phase IM was tested in constant torque control mode under the same three $\omega_{r}^{*}$ $5001 / \mathrm{min}, 10001 / \mathrm{min}$ and $15001 / \mathrm{min}$ with different WFs $\lambda_{x y}$. All tests were carried out under conditions of constant reference torque equal to the nominal torque, i.e. the current references in $d-q$ axes were set to their nominal values. The results are presented in Table $\mathrm{V}$ (for $f_{s}=16 \mathrm{kHz}$ ) and Table VI (for $f_{s}=10 \mathrm{kHz}$ ).

By analyzing Table V, it can be concluded what follows:

1) As the WF $\lambda_{x y}$ increases, for a $\omega_{r}^{*}$, the tracking errors of $i_{d}^{*}$ and $i_{q}^{*}$ are larger. The $i_{d(\text { actual })} / i_{d}^{*}$ and $i_{q(\text { actual })} / i_{q}^{*}$ ratios are reduced, and therefore the achievable torque is smaller (smaller $T_{L} / T_{L \text { (rated) }}$ ratio).

2) On the other hand, if the WF $\lambda_{x y}$ is kept constant as the $\omega_{r}^{*}$ is increased, the achievable torque is lower (lower $T_{L} / T_{L \text { (rated) }}$ ratio). This issue was already

TABLE IV

THD OF STATOR CURRENTS $\alpha-\beta$ WITH $f_{s}=10 \mathrm{KHZ}, \omega_{r}^{*}=1000$ 1/MIN.

\begin{tabular}{ccc}
\hline$\lambda_{x y}$ & $\mathrm{THD}_{\alpha}(\%)$ & $\mathrm{THD}_{\beta}(\%)$ \\
\hline \hline 0 & 3.08 & 3.37 \\
\hline 0.0150 & 3.85 & 4.02 \\
\hline 0.0177 & 3.81 & 3.91 \\
\hline 0.1 & 5.45 & 5.58 \\
\hline 1 & 12.74 & 13.15 \\
\hline
\end{tabular}




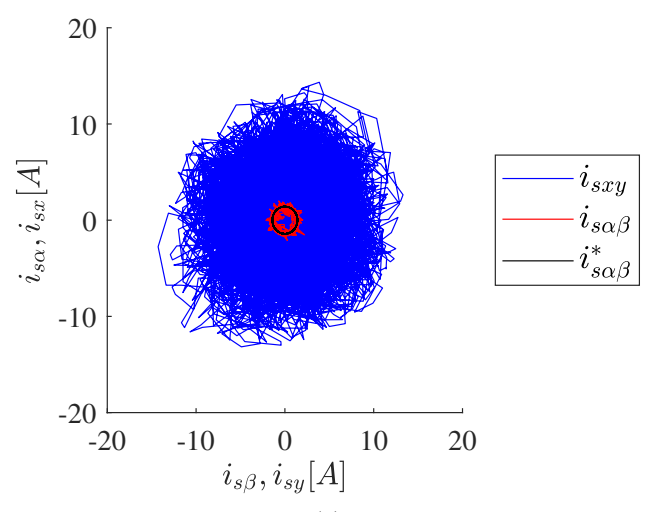

(a)

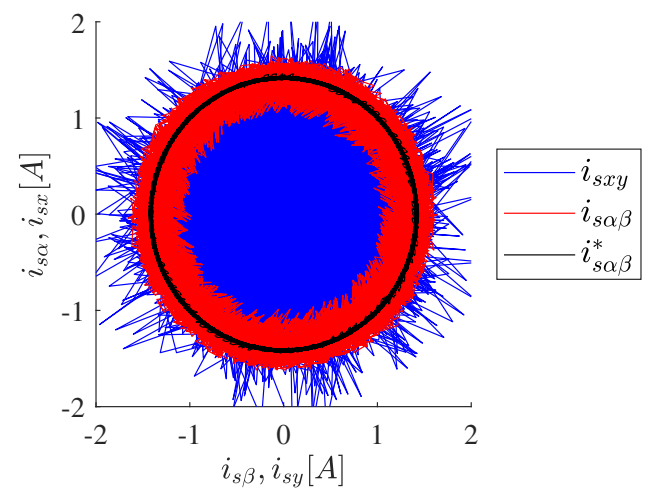

(b)

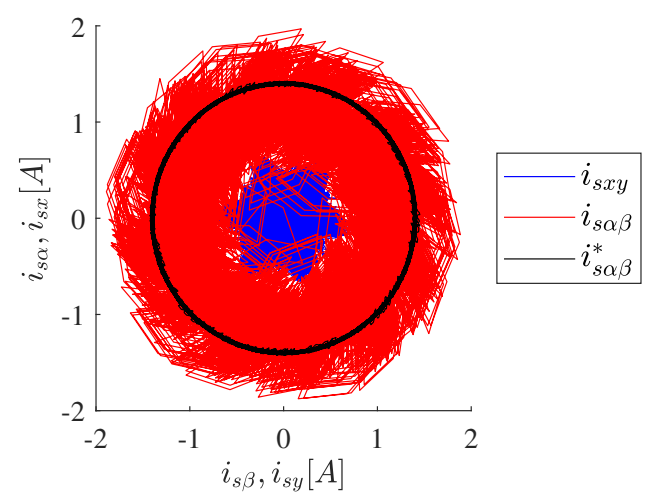

(c)

Fig. 7. Stator currents obtained with $f_{s}=10 \mathrm{kHz}, \omega_{r}^{*}=15001 / \mathrm{min}$, for (a) $\lambda_{x y}=0$, (b) $\lambda_{x y}=0.0177$, and (c) $\lambda_{x y}=1$.

explained previously and it is related to the fact that by increasing the $\omega_{r}^{*}$ the relationship between the $f_{s}$ and the fundamental frequency is reduced and therefore the performance of the current control is reduced.

3) The average switching frequency $f_{\mathrm{sw}(\operatorname{avg})}$ has a dependence inversely proportional to the modulation index (ac/dc voltage ratio). As the $\omega_{r}^{*}$ increases, the ac voltage increases and, consequently, the switching frequency $f_{\mathrm{sw}}$ decreases.

4) The $f_{\mathrm{sw}}$ increases with increasing the WF $\lambda_{x y}$. The latter helps to reduce the current ripple in both subspaces.

Table VI shows the torque characteristics analysis for $f_{s}=10 \mathrm{kHz}$. The same conclusions indicated above can be drawn from the analysis of the results included in Table V. On

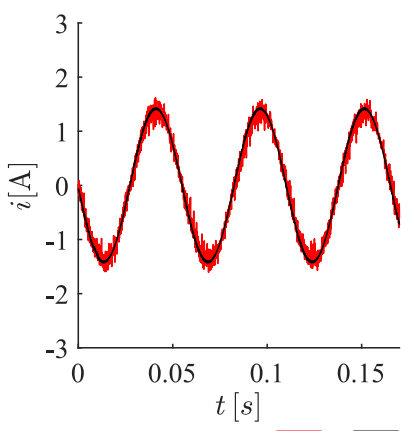

$i_{s \alpha} i_{s \alpha}^{*}$

(a)

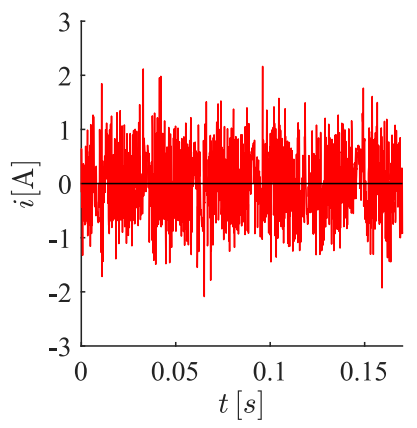

$i_{s x}^{*}$

(c)

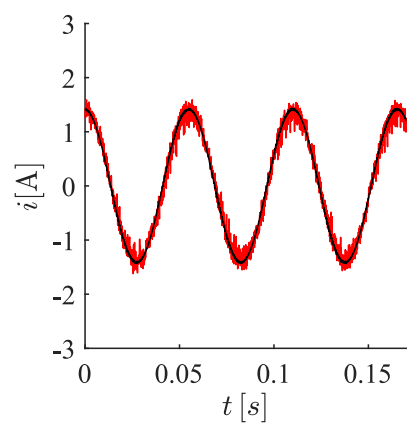

$i_{s \beta}$

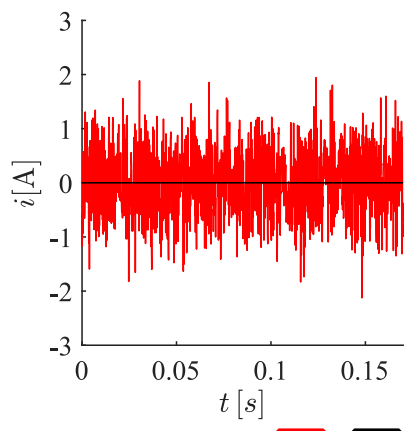

(d)

Fig. 8. Waveforms with $f_{s}=10 \mathrm{kHz}, \omega_{r}^{*}=10001 / \mathrm{min}$ and $\lambda_{x y}=0.0177$.

TABLE V

INFLUENCE OF THE WF $\lambda_{x y}$ ON THE TORQUE CHARACTERISTICS OF THE SIX-PHASE IM UNDER $f_{s}=16 \mathrm{KHz}, i_{q}^{*}=i_{q(\mathrm{rated})}$, AND $i_{d}^{*}=i_{d(\mathrm{rated})}$.

\begin{tabular}{|c|c|c|c|c|}
\hline \multicolumn{5}{|c|}{$\omega_{r}^{*}=5001 / \mathrm{min}$} \\
\hline$\lambda_{x y}$ & $\begin{array}{c}i_{q(\text { actual })} / i_{q}^{*} \\
(\mathrm{pu})\end{array}$ & $\begin{array}{c}i_{d(\mathrm{actual})} / i_{d}^{*} \\
(\mathrm{pu})\end{array}$ & $\begin{array}{c}T_{L} / T_{L(\text { rated })} \\
(\%)\end{array}$ & $\begin{array}{c}f_{\mathrm{sw}(\mathrm{avg})} \\
(\mathrm{kHz})\end{array}$ \\
\hline 0.0196 & 0.97 & 1 & $98.33 \%$ & 5.30 \\
\hline 0.1 & 0.93 & 0.98 & $96.88 \%$ & 5.30 \\
\hline 1 & 0.86 & 0.96 & $83.1 \%$ & 6.20 \\
\hline \multicolumn{5}{|c|}{$\omega_{r}^{*}=10001 / \mathrm{min}$} \\
\hline$\lambda_{x y}$ & $\begin{array}{c}i_{q(\text { actual })} / i_{q}^{*} \\
(\mathrm{pu})\end{array}$ & $\begin{array}{c}i_{d(\text { actual })} / i_{d}^{*} \\
(\mathrm{pu})\end{array}$ & $\begin{array}{c}T_{L} / T_{L(\text { rated })} \\
(\%)\end{array}$ & $\begin{array}{c}f_{\mathrm{sw}(\operatorname{avg})} \\
(\mathrm{kHz})\end{array}$ \\
\hline 0.0196 & 0.96 & 0.99 & $95.42 \%$ & 4.70 \\
\hline 0.1 & 0.89 & 0.98 & $91.04 \%$ & 4.70 \\
\hline 1 & 0.81 & 0.94 & $80.83 \%$ & 5.20 \\
\hline \multicolumn{5}{|c|}{$\omega_{r}^{*}=15001 / \mathrm{min}$} \\
\hline$\lambda_{x y}$ & $\begin{array}{c}i_{q(\text { actual })} / i_{q}^{*} \\
(\mathrm{pu})\end{array}$ & $\begin{array}{c}i_{d(\text { actual })} / i_{d}^{*} \\
(\mathrm{pu})\end{array}$ & $\begin{array}{c}T_{L} / T_{L(\text { rated })} \\
(\%)\end{array}$ & $\begin{array}{c}f_{\mathrm{sw}(\mathrm{avg})} \\
(\mathrm{kHz})\end{array}$ \\
\hline 0.0190 & 0.96 & 0.99 & $94.17 \%$ & 4.3 \\
\hline 0.1 & 0.92 & 0.98 & $91.04 \%$ & 4.30 \\
\hline 1 & 0.78 & 0.93 & $75.00 \%$ & 4.30 \\
\hline
\end{tabular}

the other hand, if the results of Table IV and those of Table V are compared, it can be seen that the reference tracking is worse for lower values of $f_{s}$ and consequently, the achievable torque for the same reference is lower. 
TABLE VI

INFLUENCE OF THE WF $\lambda_{x y}$ ON THE TORQUE CHARACTERISTICS OF THE SIX-PHASE IM UNDER $f_{s}=10 \mathrm{KHZ}, i_{q}^{*}=i_{q(\mathrm{rated})}$, AND $i_{d}^{*}=i_{d(\mathrm{rated})}$.

\begin{tabular}{|c|c|c|c|c|}
\hline \multicolumn{5}{|c|}{$\omega_{r}^{*}=5001 / \mathrm{min}$} \\
\hline$\lambda_{x y}$ & $\begin{array}{c}i_{q(\text { actual })} / i_{q}^{*} \\
(\mathrm{pu})\end{array}$ & $i_{d(\mathrm{actual})} / i_{d}^{*}$ & $\begin{array}{c}T_{L} / T_{L(\text { rated })} \\
(\%)\end{array}$ & $\begin{array}{c}f_{\mathrm{sw}(\mathrm{avg})} \\
(\mathrm{kHz})\end{array}$ \\
\hline 0.0186 & 0.96 & 0.99 & $95.42 \%$ & 3.50 \\
\hline 0.1 & 0.89 & 0.98 & $90.83 \%$ & 3.50 \\
\hline 1 & 0.72 & 0.96 & $78.33 \%$ & 4.10 \\
\hline \multicolumn{5}{|c|}{$\omega_{r}^{*}=10001 / \mathrm{min}$} \\
\hline$\lambda_{x y}$ & $\underset{(\mathrm{pu})}{i_{q(\text { actual })} / i_{q}^{*}}$ & $\underset{(\mathrm{pu})}{i_{d(\text { actual })} / i_{d}^{*}}$ & $\begin{array}{c}T_{L} / T_{L(\text { rated })} \\
(\%)\end{array}$ & $\begin{array}{c}f_{\mathrm{sw}(\mathrm{avg})} \\
(\mathrm{kHz})\end{array}$ \\
\hline 0.0177 & 0.95 & 0.99 & $94.17 \%$ & 3.10 \\
\hline 0.1 & 0.86 & 0.98 & $85.21 \%$ & 3.10 \\
\hline 1 & 0.70 & 0.94 & $73.33 \%$ & 3.50 \\
\hline \multicolumn{5}{|c|}{$\omega_{r}^{*}=15001 / \mathrm{min}$} \\
\hline$\lambda_{x y}$ & $\underset{(\mathrm{pu})}{i_{q(\text { actual })} / i_{q}^{*}}$ & $i_{d(\text { actual })} / i_{d}^{*}$ & $\begin{array}{c}T_{L} / T_{L(\text { rated })} \\
(\%)\end{array}$ & $\begin{array}{c}f_{\mathrm{sw}(\mathrm{avg})} \\
(\mathrm{kHz})\end{array}$ \\
\hline 0.0180 & 0.95 & 0.99 & $93.13 \%$ & 2.80 \\
\hline 0.1 & 0.84 & 0.98 & $83.33 \%$ & 2.80 \\
\hline 1 & 0.65 & 0.91 & $63.96 \%$ & 3.00 \\
\hline
\end{tabular}

\section{A. Transient response}

Because the design is based on the steady-state performance of the system, the obtained values of $\lambda_{x y}$ do not guarantee optimal performance during transient conditions. However, by introducing steps into $w_{r}^{*}$, simulations showed no significant changes in the system's transient behaviour. To experimentally test the controllers response under transient conditions, a step from $15001 / \mathrm{min}$ to $5001 / \mathrm{min}$ was introduced (see Fig. 9), with $f_{s}=10 \mathrm{kHz}$ and two different values for $\lambda_{x y}$, one obtained with the MOPSO $\left(\lambda_{x y}=0.018\right)$ and another one picked randomly $\left(\lambda_{x y}=0.5\right)$. Then, $i_{q}$ is measured to observe the controller performance under the transient condition. We can see in Fig. 9 that the main difference in this test lies in the steady-state behaviour, with essentially the same response in the transient. Certainly, this fact does not permit to affirm that the transient operation works optimally. Fig. 10 only shows that despite the WF has been calculated in steady-state, the transient performance does not show any perturbation or strange behaviour. Consequently, we can state that transient conditions are not critical for the design of the WF for the cost function of the PCC for this application.

\section{B. Parameters mismatch}

Because the PCC scheme is a model-based control, and given that the tuning method proposed is based on simulations of the analyzed system, parameter mismatch is an issue that must be taken into consideration. We performed a simulation study to test the proposed MOPSO method against sensitivity to parameter mismatch. We changed $L_{m}$ in the model used for the WF tuning to be $25 \%$ higher than the nominal value since $L_{m}$ is the most sensitive parameter in IMs [31]. We set $f_{s}=10 \mathrm{kHz}$ and $\omega_{r}^{*}=10001 / \mathrm{min}$. With these parameters, the Pareto Fronts shown in Fig. 11 were obtained, which differ from the ones obtained in Fig. 6. We performed steady-state and transient experiments using $\lambda_{x y}=0.0168$ and using

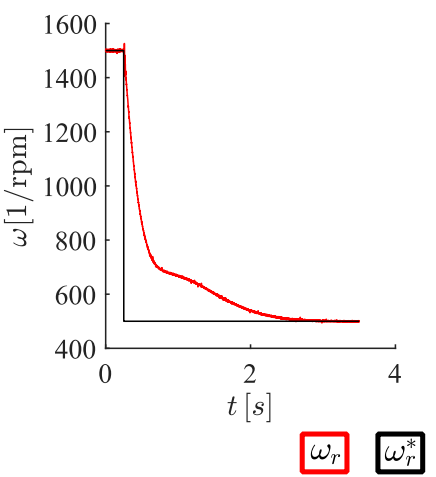

(a)

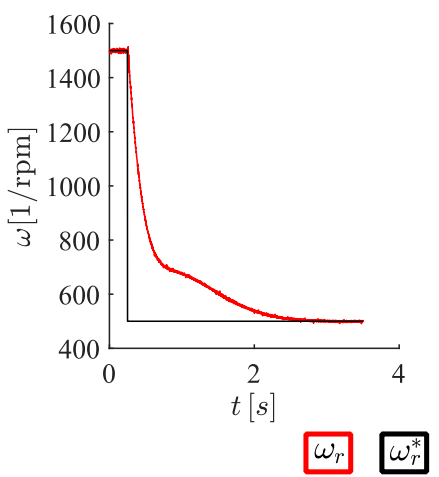

(b)
Fig. 9. xperimental measured of the rotor speed with $f_{s}=10 \mathrm{kHz}$ for a step from $15001 / \mathrm{min}$ to $5001 / \mathrm{min}$. (a) $\lambda_{x y}=0.018$ (b) $\lambda_{x y}=0.5$.

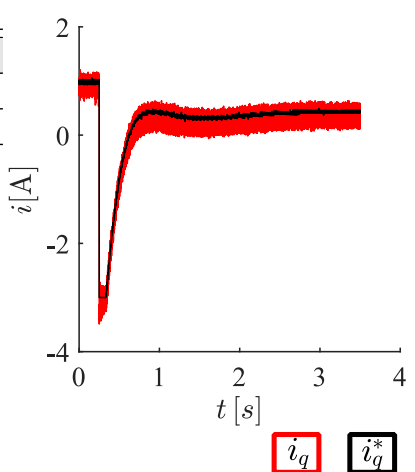

(a)

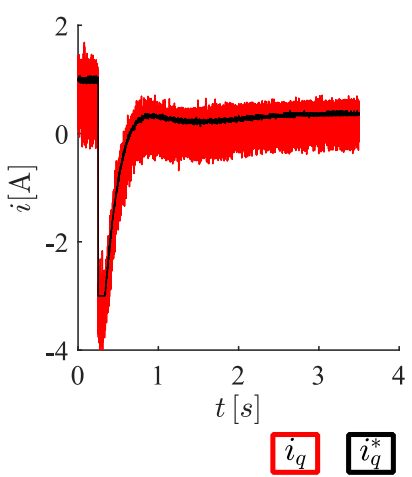

(b)
Fig. 10. Experimental transient response with $f_{s}=10 \mathrm{kHz}$ for a step from $15001 / \mathrm{min}$ to $5001 / \mathrm{min}$. (a) $\lambda_{x y}=0.018$ (b) $\lambda_{x y}=0.5$.

the same value of $L_{m}$ that was used for the tuning in the control scheme, and we obtained the results shown in Fig. 12. Though the WFs are in the same range of values as the ones obtained with the actual value of $L_{m}$, the tracking performance is affected by the control scheme's parameters mismatch, as expected. The errors, in terms of the RMSE are as follows: $\operatorname{RMSE}_{\alpha}=0.1289, \operatorname{RMSE}_{\beta}=0.1293, \operatorname{RMSE}_{x}=0.6198$, $\operatorname{RMSE}_{y}=0.6222$.

\section{Inclusion of more terms in the $C F$}

To prove that the proposed method could be extended to cases with more comprehensive cost functions, a term to limit the average switching frequency of the converters was added to the cost function, as follows:

$$
J_{1}=\left|e_{\alpha \beta}\right|^{2}+\lambda_{x y}\left|e_{x y}\right|^{2}+\lambda_{s w} S_{w}
$$

where

$$
S_{w}=\sum\left|S_{\zeta}(k)-S_{\zeta}(k+1)\right|
$$

for $\zeta=\{a, b, c, d, e, f\}$. This new term allows minimizing the number of switchings in each time sample, which ultimately limits the average switching frequency of the $2 \mathrm{~L}-\mathrm{VSI}$. The objective variables are:

$$
\mathbf{f}(\mathbf{p})=\mathbf{o}=\left[\begin{array}{c}
\operatorname{RMSE}_{\alpha \beta} \\
\operatorname{RMSE}_{x y} \\
S_{w}
\end{array}\right]=\left[\begin{array}{c}
f_{1}\left(\lambda_{x y}, \lambda_{s w}\right) \\
f_{2}\left(\lambda_{x y}, \lambda_{s w}\right) \\
f_{3}\left(\lambda_{x y}, \lambda_{s w}\right)
\end{array}\right]
$$




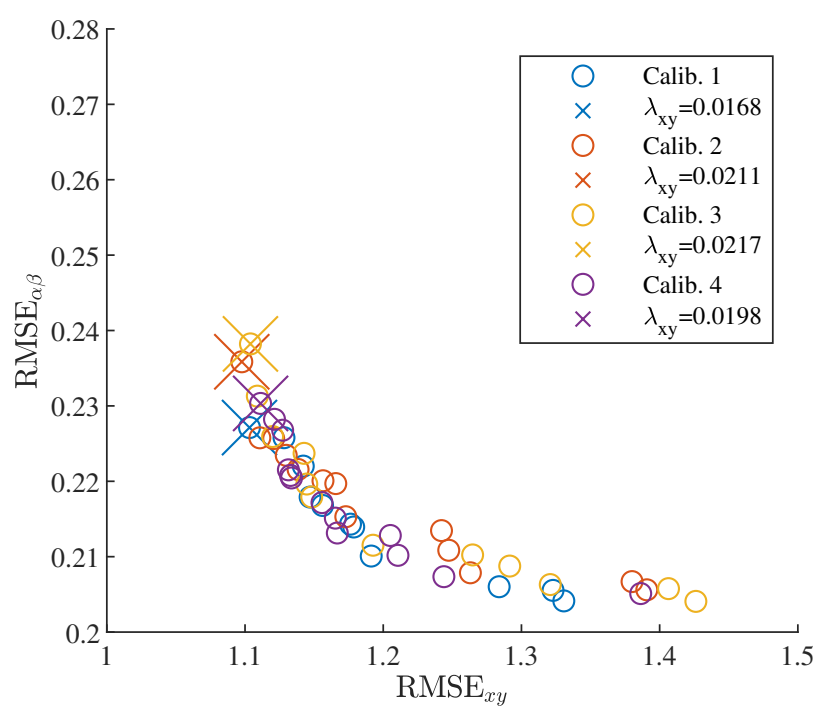

Fig. 11. Pareto front obtained with $f_{s}=10 \mathrm{kHz}$ and $\omega_{r}^{*}=10001 / \mathrm{min}$ under parameter mismatch $\left(25 \%\right.$ variation of $\left.L_{m}\right)$.
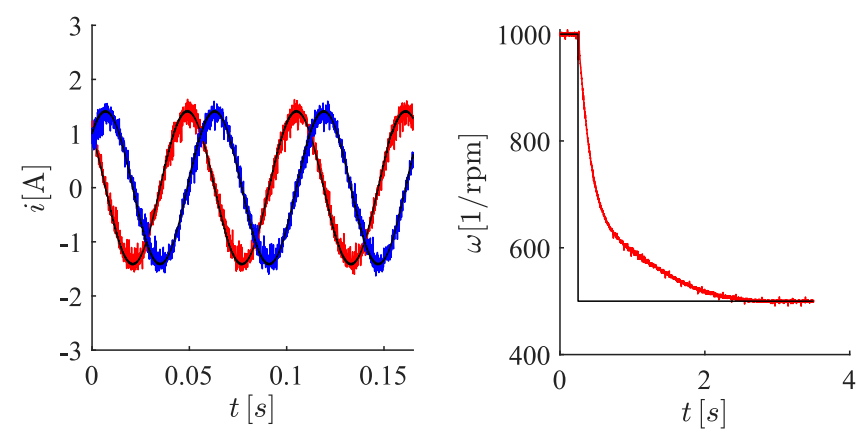

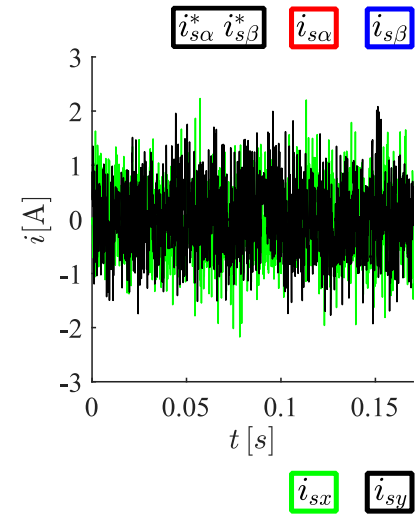

(a)

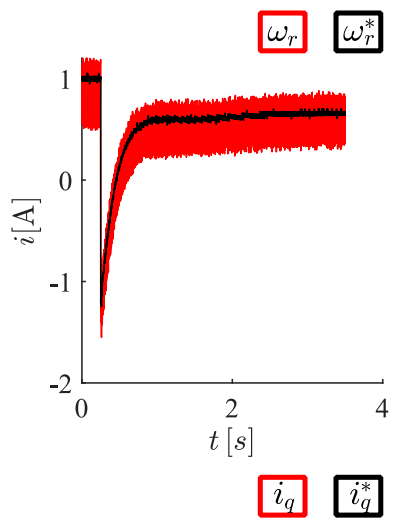

(b)
Fig. 12. Experimental results for a mismatch of $25 \%$ for $L_{m}$, obtained at $f_{s}=10 \mathrm{kHz}$ and $w_{r}^{*}=10001 / \mathrm{min}$, for $\lambda_{x y}=0.0168$. (a) Steady-state response (b) Transient response.

The chosen MOPSO parameters were the same as for the first case. However, the number of particles $N=20$, and the number of generations is 40 . Considering that the obtained Pareto fronts are now a plot in a three-dimensional space, and the addition of points allows for better legibility and a higher number of possible pairs of WF to pick. Fig. 13 shows the obtained Pareto fronts for four different calibrations, with $f_{s}=10 \mathrm{kHz}, \omega_{r}^{*}=10001 / \mathrm{min}$. As can be seen, all four calibrations generate similar Pareto fronts, meaning the

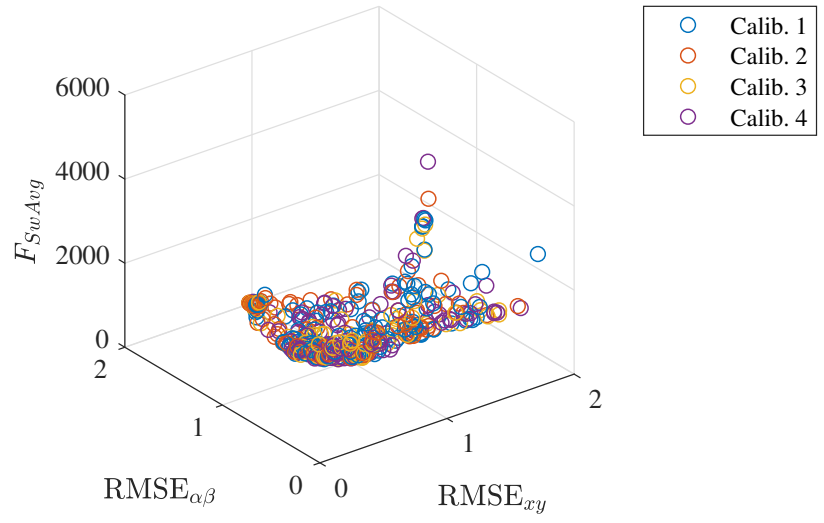

Fig. 13. Pareto fronts obtained with $f_{s}=10 \mathrm{kHz}$ for $\omega_{r}^{*}=10001 / \mathrm{min}$ using a cost function that limits the switching frequency.

algorithm converges with the chosen parameters and guarantee the repeatability of the algorithm.

In order to select a pair $\lambda_{x y}, \lambda_{s w}$ a design criteria must be defined. For this case, the used criteria was to select a pair that gives:

$\operatorname{RMSE}_{\alpha \beta}<0.5$
$\operatorname{RMSE}_{x y}<1$
$f_{s w(a v g)}<2 \mathrm{kHz}$

A pair from the Pareto front obtained in Calib. 4 that meets this criteria is $\lambda_{x y}=0.0481, \lambda_{s w}=0.2020$.

\section{Comparison between MOPSO and ANN tuning methods}

To apply the WF design approach using the ANN based method proposed in [18], several simulations runs needs to be performed to obtain the data required for the ANN training. For all possible combinations in the defined WF intervals: $\lambda_{x y}=\left[\begin{array}{lllll}0 & : & 0.05 & : & 0.25\end{array}\right]$ and $\lambda_{s w}=\left[\begin{array}{ll}0 & \text { : }\end{array}\right.$ $0.05: 0.25]$ simulations were performed, in total $2601\left(51^{2}\right)$ simulations. The task was distributed among the 10 processor cores and completed in 1.2 hours. For each WF combination performance metrics RMSE ${ }_{\alpha}, \mathrm{RMSE}_{\beta}, \mathrm{RMSE}_{x}, \mathrm{RMSE}_{y}$ and $f_{\mathrm{sw}(\mathrm{avg})}$ were stored. In the next step, these values, together with the corresponding WFs, were passed to the ANN. A shallow feedforward ANN with 10 neurons in the hidden layer, 2 neurons in the input layer, and 5 neurons in the output layer was defined and trained in MATLAB using the Neural Networks toolbox. The training was completed in $1 \mathrm{~s}$ with the regression value of 0.988 . Using the trained network, it is now possible to obtain the performance metrics for an even larger number of WFs. In the final step, fitness functions (optimisation criteria) was defined:

$$
f_{A N N}=\mathrm{RMSE}_{\alpha \beta}^{2}+\mathrm{RMSE}_{x y}^{2}
$$

The fitness function plot and the obtained optimum WF combination can be observed in Fig. 14. These were obtained for sampling frequency of $10 \mathrm{kHz}$ and reference speed of $1000 \mathrm{l} / \mathrm{min}$.

Table VII exposes the comparative performance metrics obtained for the PCC with the WFs with the performance metrics of PCC with WF selected by the ANN method and WF 


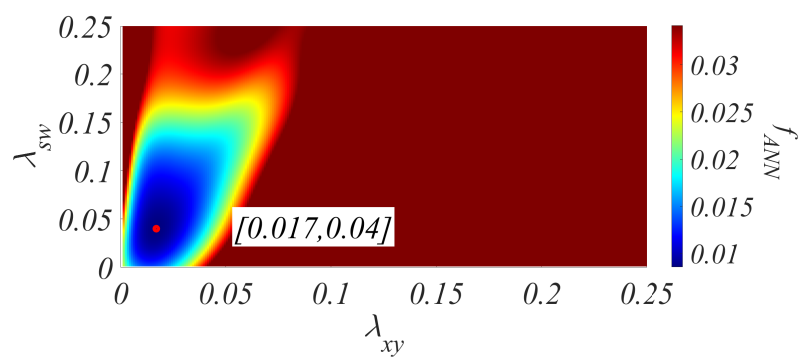

Fig. 14. Fitness function plot and the selected optimum WFs $\lambda_{x y}=0.017$ and $\lambda_{s w}=0.04$.

TABLE VII

SIMULATION AND EXPERIMENTAL PERFORMANCE METRICS COMPARISON FOR THE TWO DIFFERENT TUNING METHODS $\left(f_{s}=10 \mathrm{KHZ}\right.$, $\left.\omega_{r}^{*}=10001 / \mathrm{MIN}\right)$.

\begin{tabular}{ccccc}
\hline & \multicolumn{2}{c}{ MOPSO } & \multicolumn{2}{c}{ ANN } \\
\hline Perf. Metrics & Sim & Exp & Sim & Exp \\
\hline \hline RMSE $_{\alpha}$ & 0.2611 & 0.2757 & 0.1219 & 0.1212 \\
$\mathrm{RMSE}_{\beta}$ & 0.2534 & 0.2733 & 0.1198 & 0.1214 \\
$\mathrm{RMSE}_{x}$ & 0.5603 & 0.6736 & 0.6856 & 0.6913 \\
$\mathrm{RMSE}_{y}$ & 0.5547 & 0.6673 & 0.7030 & 0.6874 \\
\hline
\end{tabular}

selected by the MOPSO algorithm. Note that the performance metrics for the WFs selected by the ANN method also fulfil the optimisation criteria set by the MOPSO algorithm in the previous section, except for the switching frequency, which was of $f_{s w(A v g)}=2.2 \mathrm{kHz}$ for the ANN and $f_{s w(A v g)}=$ $1.5 \mathrm{kHz}$ for the MOPSO. The variation of the performance metrics is in the expected range [32].

Fig. 15 displays the waveforms obtained with each optimisation method. While the ANN method selected the WF, which produced a lower RMSE in $\alpha-\beta$ components, the MOPSO WF combination made a lower RMSE in $x-y$ components. Overall, the MOPSO WFs provided a better set of performance metrics. It's possible to pick another pair of WF from the Pareto Fronts that meet the criteria in (27) or even relaxing the switching frequency criterion to match the frequency of the ANN to get a better tracking in the $\alpha-\beta$ plane. Interestingly, when the ANN tuning method was performed for a single WF in the cost function $\left(\lambda_{x y}\right)$, the same optimum WF value was obtained as for the MOPSO method. It needs to be mentioned that during the ANN training with the dataset obtained for the cost function with two WFs, some data did not fit the regression curve in the regression plot. Thus with additional data processing, where those ambiguous datasets are removed from the training, the performance of the ANN method can be improved.

\section{CONCLUSION}

An offline optimization method for tuning the WF of a classic PCC for a six-phase IM application is presented in this paper. In this application, $\lambda_{x y}$, which is related to $x-y$ IM currents, is typically the only WF that requires tuning. The proposed is based on the MOPSO algorithm and uses
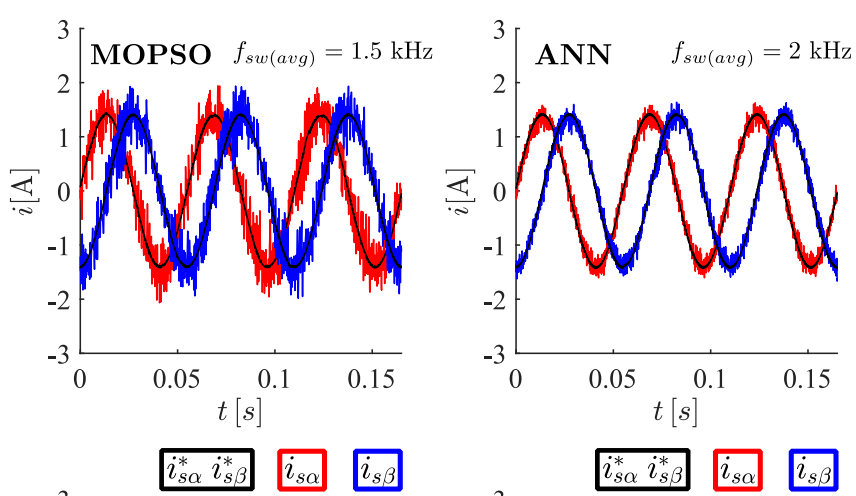

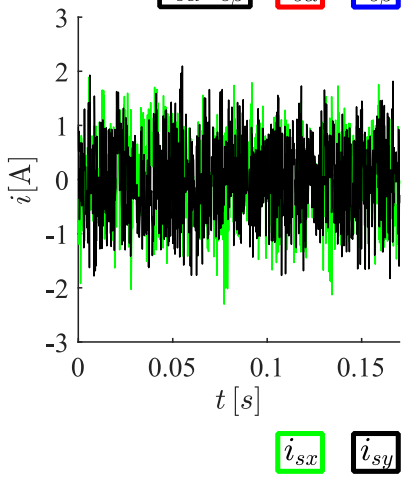

(a)

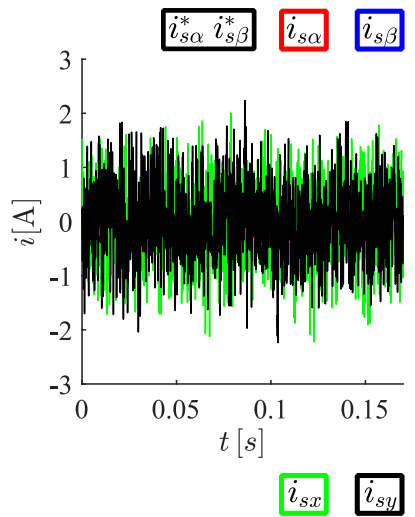

(b)
Fig. 15. Stator currents in $\alpha-\beta$ (top) and $x-y$ (bottom) planes at $10001 / \mathrm{min}$ for: (a) MOPSO (b) ANN.

Pareto optimally for its fitness function so that the user can choose a desirable solution from the Pareto front, thereby ensuring that the solutions are aligned with the purposes of the user. It has been shown that following the heuristic method, several steps are needed to narrow the selection, and even then, the whole state space is not explored. Consequently, the control designer can not be sure if some local minimum has been chosen. The obtained gain values have been analyzed experimentally in the PCC structure commonly used as an alternative to proportional-integral current control in the field-oriented-control approach. The results obtained by using the values provided by the MOPSO algorithm show better optimization of the RMS of $\alpha-\beta$ and $x-y$ IM's stator currents, compared to the results obtained by the trial and error method. Moreover, through a proper tuning of the WF, the user can maximize the achievable torque and, at the same time, minimize the reference tracking and the RMSE.

We demonstrated that with slight modifications, the MOPSO algorithm could include more terms in the cost function. A brief comparison with an ANN method has been discussed, showing similar results. The latter gave us the motivation to address an exhaustive comparison of the proposed MOPSO method against other Pareto-based technique (e.g. [33]) and the ANN method and/or NSGA-II as a near-future research topic.

\section{REFERENCES}

[1] M. J. Duran, E. Levi, and F. Barrero, "Multiphase electric drives: Introduction," Wiley encyclopedia of electrical and electronics engineering, pp. 1-26, 2017. 
[2] E. Levi, "Advances in converter control and innovative exploitation of additional degrees of freedom for multiphase machines," IEEE Transactions on Industrial Electronics, vol. 63, no. 1, pp. 433-448, 2015.

[3] F. Barrero and M. J. Duran, "Recent advances in the design, modeling, and control of multiphase machines-Part I," IEEE Transactions on Industrial Electronics, vol. 63, no. 1, pp. 449-458, 2016.

[4] P. Gonçalves, S. Cruz, and A. Mendes, "Finite control set model predictive control of six-phase asymmetrical machines-an overview," Energies, vol. 12, no. 24, p. 4693, 2019.

[5] M. Bermúdez, C. Martín, I. González-Prieto, M. J. Durán, M. R. Arahal, and F. Barrero, "Predictive current control in electrical drives: an illustrated review with case examples using a five-phase induction motor drive with distributed windings," IET Electric Power Applications, vol. 14, no. 8, pp. 1291-1310, 2020.

[6] M. Jones, S. N. Vukosavic, D. Dujic, and E. Levi, "A synchronous current control scheme for multiphase induction motor drives," IEEE Transactions on Energy Conversion, vol. 24, no. 4, pp. 860-868, 2009.

[7] M. Arahal, F. Barrero, S. Toral, M. Duran, and R. Gregor, "Multi-phase current control using finite-state model-predictive control," Control Engineering Practice, vol. 17, no. 5, pp. 579-587, 2009.

[8] M. J. Duran, J. Prieto, F. Barrero, and S. Toral, "Predictive current control of dual three-phase drives using restrained search techniques," IEEE Transactions on Industrial Electronics, vol. 58, no. 8, pp. 3253-3263, 2010.

[9] J. Rodas, F. Barrero, M. R. Arahal, C. Martín, and R. Gregor, "Online estimation of rotor variables in predictive current controllers: A case study using five-phase induction machines," IEEE Transactions on Industrial Electronics, vol. 63, no. 9, pp. 5348-5356, 2016.

[10] O. Gonzalez, M. Ayala, J. Doval-Gandoy, J. Rodas, R. Gregor, and M. Rivera, "Predictive-fixed switching current control strategy applied to six-phase induction machine," Energies, vol. 12, no. 12, p. 2294, 2019.

[11] I. Gonzalez-Prieto, M. J. Duran, J. J. Aciego, C. Martin, and F. Barrero, "Model predictive control of six-phase induction motor drives using virtual voltage vectors," IEEE Transactions on Industrial Electronics, vol. 65 , no. 1 , pp. $27-37,2017$.

[12] M. Ayala, J. Doval-Gandoy, J. Rodas, O. Gonzalez, R. Gregor, and M. Rivera, "A novel modulated model predictive control applied to six-phase induction motor drives," IEEE Transactions on Industrial Electronics, vol. 68, no. 5, pp. 3672-3682, 2021.

[13] J. A. Riveros, F. Barrero, E. Levi, M. J. Durán, S. Toral, and M. Jones, "Variable-speed five-phase induction motor drive based on predictive torque control," IEEE Transactions on Industrial Electronics, vol. 60, no. 8, pp. 2957-2968, 2012.

[14] Y. Luo and C. Liu, "Pre- and post-fault tolerant operation of a six-phase PMSM motor using FCS-MPC without controller reconfiguration," IEEE Transactions on Vehicular Technology, vol. 68, no. 1, pp. 254-263, 2019.

[15] M. R. Arahal, F. Barrero, M. J. Duran, M. G. Ortega, and C. Martín, "Trade-offs analysis in predictive current control of multi-phase induction machines," Control Engineering Practice, vol. 81, pp. 105-113, 2018.

[16] J. Rodriguez and P. Cortes, Predictive control of power converters and electrical drives. John Wiley \& Sons, 2012, vol. 40.

[17] P. Cortés, S. Kouro, B. La Rocca, R. Vargas, J. Rodríguez, J. I. León, S. Vazquez, and L. G. Franquelo, "Guidelines for weighting factors design in model predictive control of power converters and drives," in 2009 IEEE International Conference on Industrial Technology, 2009, pp. 1-7.

[18] T. Dragičević and M. Novak, "Weighting factor design in model predictive control of power electronic converters: An artificial neural network approach," IEEE Transactions on Industrial Electronics, vol. 66, no. 11 , pp. $8870-8880,2018$.

[19] P. Karamanakos and T. Geyer, "Guidelines for the design of finite control set model predictive controllers," IEEE Transactions on Power Electronics, vol. 35, no. 7, pp. 7434-7450, 2019.

[20] C. S. Lim, E. Levi, M. Jones, N. A. Rahim, and W. P. Hew, "FCS-MPC-based current control of a five-phase induction motor and its comparison with PI-PWM control," IEEE Transactions on Industrial Electronics, vol. 61, no. 1, pp. 149-163, 2013.

[21] Y. Zhao and T. Lipo, "Space vector PWM control of dual three-phase induction machine using vector space decomposition," IEEE Transactions on Industry Applications, vol. 31, no. 5, pp. 1100-1109, 1995.

[22] J. Rodas, C. Martín, M. R. Arahal, F. Barrero, and R. Gregor, "Influence of covariance-based ALS methods in the performance of predictive controllers with rotor current estimation," IEEE Transactions on Industrial Electronics, vol. 64, no. 4, pp. 2602-2607, 2017.
[23] P. Tripathi, S. Bandyopadhyay, and S. Pal, "An adaptive multi-objective particle swarm optimization algorithm with constraint handling," Handbook of Swarm Intelligence. Adaptation, Learning, and Optimization, vol. 8, pp. 221-239, 2011.

[24] M. I. Hlal, V. K. Ramachandaramurthya, S. Padmanaban, H. R. Kaboli, A. Pouryekta, T. Abdullah, and T. Ab Rashid, "NSGA-II and MOPSO based optimization for sizing of hybrid pv/wind/battery energy storage system," International Journal of Power Electronics and Drive Systems, vol. 1 , no. 1 , pp. 463-478, 2019.

[25] A. Nourbakhsh, H. Safikhani, and S. Derakhshan, "The comparison of multi-objective particle swarm optimization and nsga ii algorithm: applications in centrifugal pumps," Engineering Optimization, vol. 43, no. 10 , pp. 1095-1113, 2011

[26] V. Gomez, N. Gomez, J. Rodas, E. Paiva, M. Saad, and R. Gregor, "Pareto optimal PID tuning for Px4-based unmanned aerial vehicles by using a multi-objective particle swarm optimization algorithm," Aerospace, vol. 7, no. 6, p. 71, 2020.

[27] J. Kennedy and R. Eberhart, "Particle swarm optimization," in IEEE Proceedings of ICNN'95-International Conference on Neural Networks, vol. 4, 1995, pp. 1942-1948.

[28] T. T. Mac, C. Copot, T. T. Duc, and R. De Keyser, "AR.Drone UAV control parameters tuning based on particle swarm optimization algorithm," in 2016 IEEE International Conference on Automation, Quality and Testing, Robotics (AQTR). IEEE, 2016, pp. 1-6.

[29] J. E. Alvarez-Benitez, R. M. Everson, and J. E. Fieldsend, "A MOPSO algorithm based exclusively on pareto dominance concepts," in International Conference on Evolutionary Multi-Criterion Optimization. Springer, 2005, pp. 459-473.

[30] C. C. Coello and M. S. Lechuga, "MOPSO: A proposal for multiple objective particle swarm optimization," in IEEE Proceedings of the 2002 Congress on Evolutionary Computation, vol. 2, 2002, pp. 1051-1056.

[31] L. Delorme, M. Ayala, J. Rodas, R. Gregor, O. Gonzalez, and J. Doval-Gandoy, "Comparison of the effects on stator currents between continuous model and discrete model of the three-phase induction motor in the presence of electrical parameter variations," in 2020 IEEE International Conference on Industrial Technology (ICIT), 2020, pp. 151-156.

[32] G. I. Rivas-Martínez, J. Rodas, and J. D. Gandoy, "Statistical Tools to Evaluate the Performance of Current Control Strategies of Power Converters and Drives," IEEE Transactions on Instrumentation and Measurement, vol. 70, pp. 1-11, 2021.

[33] P. Santis, D. Sáez, R. Cárdenas, and A. Núñez, "Pareto-based modulated model predictive control strategy for power converter applications," Electric Power Systems Research, vol. 171, pp. 158-174, 2019.

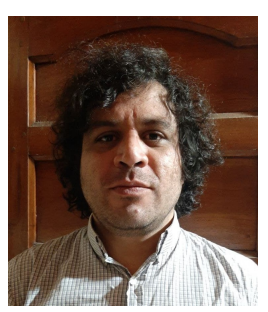

Hector Fretes was born in Asuncion, Paraguay, in 1990. He received his Engineer degree in mechatronics engineering from the Universidad Nacional de Asuncion (UNA), Paraguay, in 2018. He received his M.Sc. degree in Electronic Engineering from the Universidad del Cono Sur de las Americas, Asuncion, Paraguay, in 2020.

$\mathrm{He}$ worked in the Laboratory of Power and Control Systems (LSPyC), Faculty of Engineering, UNA, as a junior researcher. He serves as a teacher and teaching assistant at UNA since 2018. His research interests include predictive control and power electronics. 


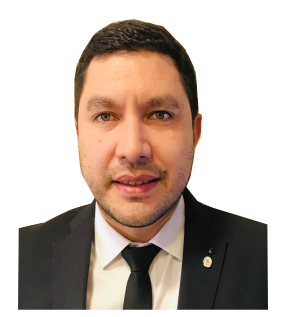

Jorge Rodas (S'08-M'12-SM'19) was born in Asunción, Paraguay, in 1984. He received his Engineer degree in electronic engineering from the Universidad Nacional de Asunción (UNA), Paraguay, in 2009. He received his M.Sc. degrees from the Universidad de Vigo, Spain, in 2012 and from the Universidad de Sevilla, Spain, in 2013, and his joint-university Ph.D. degree between the Universidad Nacional de Asunción and the Universidad de Sevilla in 2016.

In 2011, he joined the Laboratory of Power and Control Systems (LSPyC), Faculty of Engineering, UNA, where he currently serves as a professor. In 2017 he made a research stay at the Power Electronics and Industrial Control Research Group, École de Technologie Supérieure, Montreal, Canada. He serves as an Associate Editor of Elsevier Alexandria Engineering Journal and Guest Editor in the MDPI World Electric Vehicle Journal and frontiers in Energy Research. He served as Guest Editor of MDPI Energies. In 2020, Prof. Rodas received the Paraguayan National Science Award.

His research interests focus on applications of advanced control to real-world problems. Current research activities include applying model-based predictive control and nonlinear control to power electronic converters, renewable energy conversion systems, electric motor drives and robotic systems (especially drones).

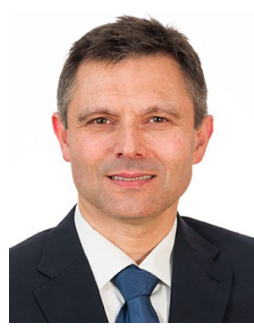

Jesús Doval-Gandoy (Member, IEEE) received the M.Sc. and Ph.D. degrees in electrical engineering from the Polytechnic University of Madrid, Madrid, Spain, and from Universidade de Vigo, Vigo, Spain, in 1991 and 1999, respectively. He is a Professor and the Head of the Applied Power Electronics Technology Research Group (APET), Universidade de Vigo. His research interests are in the areas of ac power conversion.

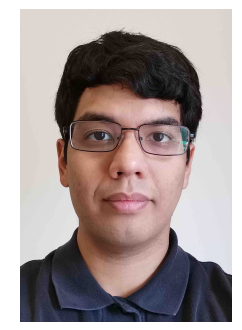

Victor Gomez was born in Asuncion, Paraguay in 1994. He received Engineer degree in mechatronics engineering from the Universidad Nacional de Asunción (UNA), Paraguay, in 2020. He is currently pursuing his M. Sc. degree in Electronics Engineering at the same university. His research interests focus on the study, proposal and experimental validation of advanced digital control techniques and optimization algorithms applied to highly nonlinear systems such as drones and multiphase machines.

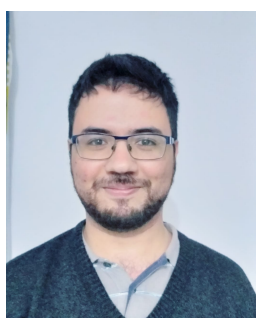

Nicolas Gomez was born in Asuncion, Paraguay. $\mathrm{He}$ received Engineer degree in mechatronics engineering from the Universidad Nacional de Asunción (UNA), Paraguay, in 2020. In 2019 and 2020, he joined the Laboratory of Power and Control Systems (LSPyC), Faculty of Engineering, UNA, as a Junior Researcher. His research interests focus on optimization algorithms.

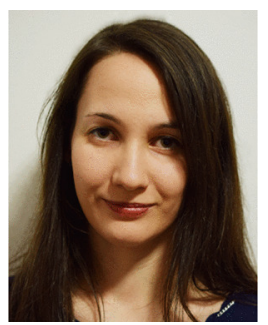

Mateja Novak (S'17-M'21) received the M.Sc. degree in Electrical Engineering and Information Technology from Zagreb University, Croatia, in 2014 and the Ph.D degree in Electrical Engineering from Aalborg University, Denmark, in 2020.

She was working as a Research Associate with the Faculty of Electrical Engineering and Computing, Zagreb University, until 2016. In 2018, she was a Visiting Researcher with the Chair of Power Electronics, Kiel University, Kiel, Germany. Currently, she is a Postdoctoral Researcher with the AAU Energy, Aalborg University. Her research interests include model predictive control, multilevel converters, statistical model checking, reliability of power electronic systems and renewable energy systems.

Dr. Novak is the recipient of EPE Outstanding Young EPE Member Award for the year 2019 .

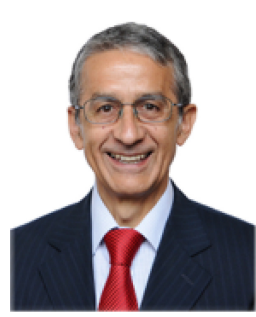

Jose Rodriguez (M'81-SM'94-F'10-LF'20) received the Engineer degree in electrical engineering from the Universidad Tecnica Federico Santa Maria, in Valparaiso, Chile, in 1977 and the Dr.-Ing. degree in electrical engineering from the University of Erlangen, Erlangen, Germany, in 1985. He has been with the Department of Electronics Engineering, Universidad Tecnica Federico Santa Maria, since 1977, where he was full Professor and President. Since 2015 he was the President and since 2019 he is full professor at Universidad Andres Bello in Santiago, Chile. He has coauthored two books, several book chapters and more than 400 journal and conference papers. His main research interests include multilevel inverters, new converter topologies, control of power converters, and adjustable-speed drives. He has received a number of best paper awards from journals of the IEEE. Dr. Rodriguez is member of the Chilean Academy of Engineering. In 2014 he received the National Award of Applied Sciences and Technology from the government of Chile. In 2015 he received the Eugene Mittelmann Award from the Industrial Electronics Society of the IEEE. In years 2014 to 2020 he has been included in the list of Highly Cited Researchers published by Web of Science.

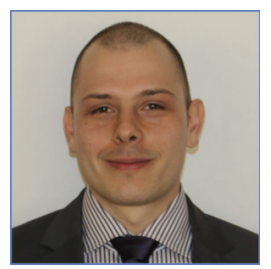

Tomislav Dragičević (S'09-M'13-SM'17) received the M.Sc. and the industrial Ph.D. degrees in Electrical Engineering from the Faculty of Electrical Engineering, University of Zagreb, Croatia, in 2009 and 2013, respectively. From 2013 until 2016 he has been a Postdoctoral researcher at Aalborg University, Denmark. From 2016 until 2020 he was an Associate Professor at Aalborg University, Denmark. Currently, he is a Professor at the Technical University of Denmark.

He made a guest professor stay at Nottingham University, UK during spring/summer of 2018. His research interest is application of advanced control, optimization and artificial intelligence inspired techniques to provide innovative and effective solutions to emerging challenges in design, control and diagnostics of power electronics intensive electrical distributions systems and microgrids. He has authored and co-authored more than 300 technical publications (more than 150 of them are published in international journals, mostly in IEEE), 10 book chapters and a book in the field.

$\mathrm{He}$ serves as an Associate Editor in the IEEE TRANSACTIONS ON INDUSTRIAL ELECTRONICS, in IEEE TRANSACTIONS ON POWER ELECTRONICS, in IEEE Emerging and Selected Topics in Power Electronics and in IEEE Industrial Electronics Magazine. Dr. Dragičević is a recipient of the Končar prize for the best industrial PhD thesis in Croatia, a Robert Mayer Energy Conservation award, and he is a winner of an Alexander von Humboldt fellowship for experienced researchers. 